\title{
Phase 0/microdosing approaches: time for mainstream application in drug development?
}

\section{Tal Burt (D), Graeme Young (D), Wooin Lee, Hiroyuki Kusuhara, Oliver Langer, Malcolm Rowland and Yuichi Sugiyama}

Abstract | Phase 0 approaches - which include microdosing - evaluate subtherapeutic exposures of new drugs in first-in-human studies known as exploratory clinical trials. Recent progress extends phase 0 benefits beyond assessment of pharmacokinetics to include understanding of mechanism of action and pharmacodynamics. Phase 0 approaches have the potential to improve preclinical candidate selection and enable safer, cheaper, quicker and more informed developmental decisions. Here, we discuss phase 0 methods and applications, highlight their advantages over traditional strategies and address concerns related to extrapolation and developmental timelines. Although challenges remain, we propose that phase 0 approaches be at least considered for application in most drug development scenarios.

Reducing attrition in clinical development is the single most important challenge in increasing pharmaceutical industry productivity ${ }^{1-5}$. A key strategy to reducing attrition rates is to improve the quality of candidates entering clinical development ${ }^{6-8}$. A phase 0 stage, so named because it is positioned between preclinical and phase I stages (TABLE 1), has the potential to improve preclinical candidate selection by applying approaches such as subtherapeutic microdosing $(100 \mu \mathrm{g}$ or less) to provide human in vivo data on pharmacokinetics, pharmacodynamics and target engagement earlier in the development process than with traditional approaches. Phase 0 approaches also have the potential to provide data that is not readily available with traditional approaches. These include first-in-human testing in patients, simultaneous testing of multiple drug candidates (known as cassette microdosing), intravenous administration of oral drugs and intratarget microdosing (ITM; the administration of microdoses locally to generate momentarily therapeutic level exposures in targets of interest $)^{9-18}$. These advantages allow triaging of preclinical candidates for entry into clinical development in a more informed, timely and effective manner.

Phase 0 approaches (FICS 1,2; TABLE 1) were introduced in 2003 (REFS ${ }^{19-21}$ ). This was soon followed by harmonized regulatory guidelines from agencies in the three main jurisdictions (USA, Europe and Japan) ${ }^{22-25}$. The emergence of phase 0 approaches coincides with a period in drug development that witnessed exponential and sometimes prohibitive increases in costs, thus risking stagnation of innovation ${ }^{1}$. Such costs were especially pronounced in the translation and clinical development stages, and regulators were encouraged to contribute to and facilitate these processes. Guidelines such as the 2006 exploratory investigational new drug (eIND) document were issued, which highlighted the flexibility in the existing regulations around data included in IND applications, and noted that sponsors had not taken full advantage of that flexibility ${ }^{23}$. The guidelines also listed a range of phase 0 approaches, including microdosing, that could enable sponsors to rapidly, safely and cheaply obtain preliminary and exploratory information about their drugs in first-inhuman studies to inform decisions about candidate selection and development.
Adoption of phase $0 /$ microdosing approaches by drug developers has been limited by uncertainty about the impact of non-linearity on extrapolation from subtherapeutic to therapeutic-level exposures, the perception that only pharmacokinetic data can be obtained with these approaches and the concern that application of phase 0 approaches will lead to delays in developmental timelines ${ }^{26,27}$. However, a range of research projects have since been conducted to optimize the effectiveness of extrapolation, expand the range of applications, including the study of pharmacodynamics, biomarkers and mechanism of action (MOA), and improve the versatility of strategic planning (for example, with the use of adaptive phase 0/phase I designs ${ }^{28-35}$. Such efforts included the formation of consortia and networks dedicated to phase $0 /$ microdosing approaches (TABLE 2).

Results of validation efforts demonstrate prediction of therapeutic-level drug disposition following microdose administration in $68 \%$ or $94 \%$ of cases depending on whether the administration is enteral or parenteral, respectively ${ }^{36}$. In addition, greater insight into non-linear mechanisms, their impact on extrapolation of subtherapeutic to therapeutic-level exposures and their management through modelling further increased the reliability and validity of extrapolation ${ }^{29,33,37-40}$ (discussed further later). In parallel, academic and commercial entities continued research into methods and applications s $^{18,41-96}$ (Supplementary information A) to expand the effectiveness of these approaches, and sponsors have increasingly used phase 0 approaches in developmental scenarios not effectively addressed by traditional approaches ${ }^{9-14,16,35,37,38,41,97-137}$ (TABLE 3; Supplementary information A).

Potential delays to developmental timelines have been managed mostly by strategic planning and parallel development. As has been previously reported and is illustrated in FIG. 2, planning for phase 0 application should optimally start 1.5-2 years before IND filing and should be done in parallel with preparations for phase I (REFS ${ }^{33,138,139}$ ). Early planning should account for validation of targets, biomarkers and analytics that may be used in phase 0 as well 
Table 1 | Specifications of the five phase 0 approaches in the ICH M3 guidelines

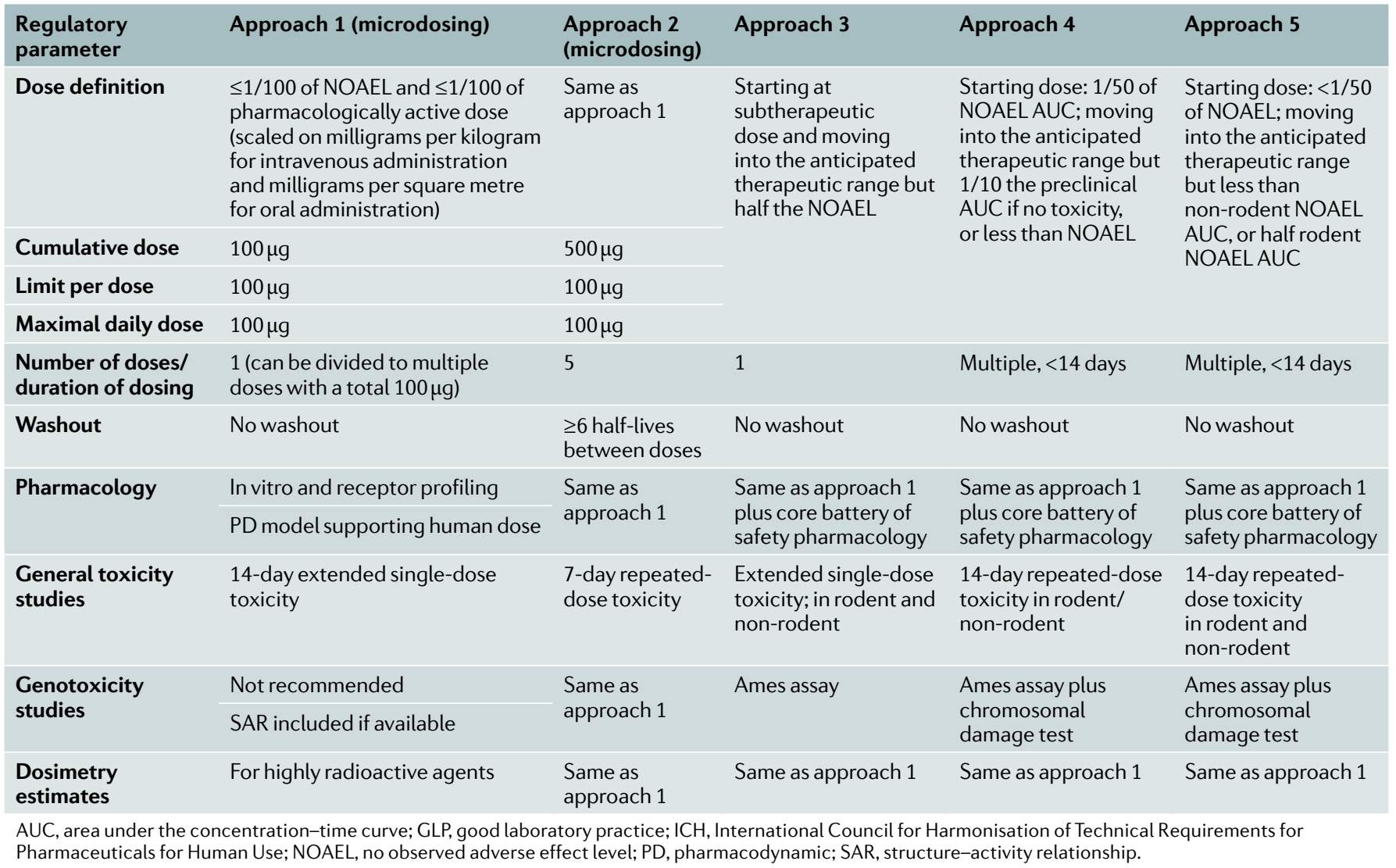

as, if needed, any associated radiochemistry for labelling of drug and/or targets.

Execution of phase 0 in parallel with phase I preparations enables the maintenance of phase I timelines, while providing the opportunity for early termination before initiation of phase I (FIG. 2). In cases in which the phase 0 studies are expected to result in significant delays to phase I timelines, a dedicated benefit-risk assessment needs to be made to evaluate whether the value of the data obtained with phase 0 is worth the delay to phase I.

This Perspective summarizes current methods, applications and research directions for phase $0 /$ microdosing approaches. The potential for mainstream application of these approaches to increase the efficiency and effectiveness of the drug development process, as well as the associated challenges and limitations, is discussed.

\section{Fundamentals of phase $\mathbf{0}$ approaches}

The FDA's 2006 eIND guidance became synonymous in the drug development community with the concept of phase 0 , or what the current harmonized International Council for Harmonisation of Technical Requirements for Pharmaceuticals for Human Use (ICH) M3 guidance calls 'exploratory clinical trials ${ }^{25}$. In this guidance, the FDA set the framework for a range of approaches that use subtherapeutic exposures to study drug effects in humans. The subtherapeutic exposures allow a much-restricted preclinical package to be submitted with an eIND application, thereby saving time and resources. The FDA justified such reductions in preclinical requirements with the inherent safety of phase 0 approaches. With 'microdosing' - the most restrictive phase 0 approach and the one offering the greatest reduction in preclinical requirements - the regulators justified the leniency with the exposures typically being equivalent to that of routine environmental exposures ${ }^{23}$.

Phase 0 studies have no therapeutic intent and are not intended to study drug safety or tolerance, but are aimed at providing preliminary information about drug pharmacokinetics, target engagement, MOA and pharmacodynamics ${ }^{16,17,34,97,98,110}$. Importantly, phase 0 enables these properties - which are critical to informed drug development decision-making - to be immediately studied in patients (that is, the target population), while phase I studies are normally conducted in healthy volunteers ${ }^{25}$. Phase 0 studies are usually smaller, shorter and cheaper than conventional phase I studies. They are typically single-cohort studies with 4-12 participants that can be completed in 1 month or less, with the entire programme potentially lasting 6-8 months. The studies are usually conducted at a single site, with the entire programme costs (including preclinical studies) being a fraction of those for a typical phase I programme and being upwards of US $\$ 350,000$. The costs for the clinical study often depend mostly on the use of the ultrasensitive analytical tools required to quantify drug disposition following subtherapeutic exposures ${ }^{139}$. This compares with conventional phase I programmes, which have larger preclinical package requirements, are more often multicohort and multisite studies, larger (30 or more participants), longer (programme duration 12-24 months) and more expensive (upwards of US\$1.5 million).

\section{Regulatory framework}

The current ICH M3 guidance provides an internationally harmonized regulatory framework for the application of phase 0 approaches $^{25}$. TABLE 3 in the ICH M3 guidelines outlines the range of possible phase 0 approaches on the continuums of 
dose and duration of exposure, from the least exposure of a single microdose (which at most is the lower of $100 \mu \mathrm{g}, 1 / 100$ of the no observed adverse effect level (NOAEL) or $1 / 100$ of the pharmacologically active dose) through to the 14-day NOAEL area under the concentration-time curve (AUC) in a non-rodent species or half the NOAEL area under the concentration-time curve in a rodent species, whichever is lower ${ }^{25}$ (FIG. 1).

\section{Operational and ethical aspects}

Many operational aspects of phase 0 approaches are similar to those of phase I approaches, including assessments, procedures, monitoring and reporting, and have been covered extensively elsewhere ${ }^{33,138,139}$. In addition, many ethical aspects of phase 0 approaches, such as informed consent, autonomy, privacy and approvals by ethics committees or institutional review boards, are also similar to those of traditional approaches. However, the inherent safety and lack of therapeutic effect have unique ethical implications, such as potential arrival at developmental decisions with reduced exposure to unnecessary risk, emphasis on altruism as the main volunteering motivator and the only minimal increase over minimal risk in paediatric patients (that is, meeting the ethical requirement for testing in paediatric patients ${ }^{140}$ ). In addition, phase 0 approaches can lead to reduced use of animals in human drug development ${ }^{138}$. Of course, the potential for increased efficiency of drug development may mean increased health care benefits and increased ethical benefit-risk balance, topics discussed in greater detail elsewhere ${ }^{33,138,140-143}$.

\section{Analytical tools}

The low doses and exposure levels used in phase 0 approaches, and especially in microdosing, necessitate sensitive analytical tools to detect drug disposition and effects in humans. This has been achieved by positron emission tomography (PET), accelerator mass spectrometry (AMS), liquid chromatography-tandem mass spectrometry, cavity ring-down spectroscopy and near-infrared fluorescent imaging (BOX 1), which have been reviewed extensively elsewhere ${ }^{19,139,144-150}$.

\section{Data extrapolation}

Since phase 0 approaches use subtherapeutic drug exposures, accurate and successful extrapolation of study results to therapeuticlevel exposures is required. To address this requirement, the key objectives of phase 0 methodological research have been to compare results for approved drug compounds in microdose and therapeutic dose exposures and to develop mathematical modelling and simulations to enhance the validity of extrapolations. Such modelling and simulations can be performed with data from in vitro transport, metabolism and binding studies in human tissues and cells as well as data from preclinical animal studies. Consortia and their projects were created primarily to accomplish these objectives (TABLE 2).

A 2019 meta-analysis of 46 compounds studied at microdoses and therapeutic doses demonstrated linear pharmacokinetics, hence allowing directly proportionate scaling within a twofold range (the standard for allometric scaling) in $68 \%$ of the compounds administered orally $(n=41)$ and $94 \%$ of the compounds administered intravenously $(n=16)^{36}$. This is generally better than alternative techniques, such as allometry, which at best is successful only $45 \%$ of the time $\mathrm{e}^{151}$. Intravenous pharmacokinetics is almost always linear at therapeutic doses, owing to dilution of the drug within the body to concentrations below those saturating enzymes and transporters. The sources of non-linearity are twofold, saturation of absorption, distribution, metabolism and excretion (ADME) processes at high doses, and saturation of the target at low doses (often referred to as 'target-mediated drug disposition' (TMDD)). However, to make valid predictions, extrapolations need not be linear. A framework exists for identifying the likelihood of non-linearity of ADME processes on the basis of the anticipated therapeutic dose coupled with in vitro assessments ${ }^{152}$, while approaches for identifying and incorporating TMDD are considered later in this Perspective. Both sources of non-linearity can be incorporated into pharmacokinetic prediction of therapeutic doses through physiologically based pharmacokinetic (PBPK) modelling and simulation, which has made considerable progress in recent years (see later, FIG. 3 and Supplementary information C) $)^{37-40}$. Since the different approaches (microdosing and PBPK modelling) use non-overlapping sources of data and theoretical constructs, they are often complementary and indeed synergistic when used together (BOX 2).

PBPK modelling. PBPK models are built with physiological parameters (for example, tissue volume and blood flow rate) and drugdependent parameters (for example, plasma/ tissue binding, metabolism, transport often obtained in vitro using human tissues or enzyme-/transporter-expression systems, and solubility and dissolution data in biorelevant media). Any of a large array

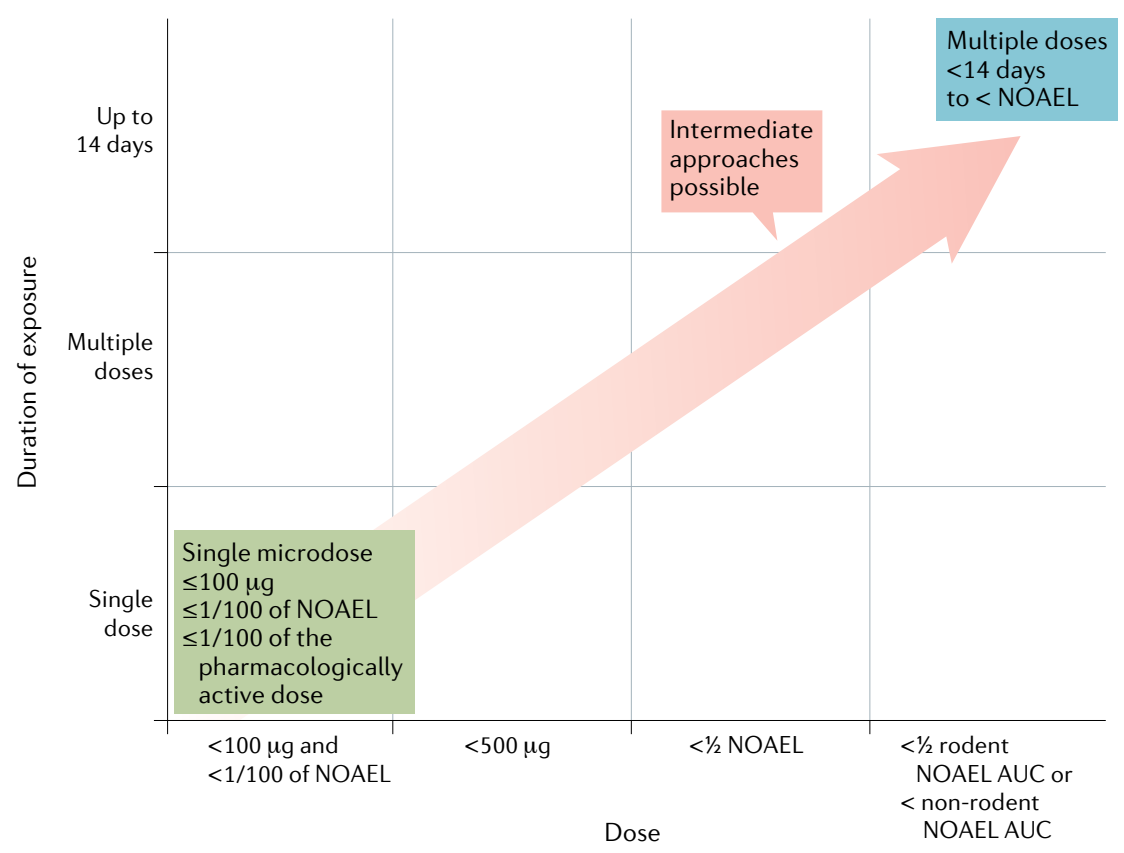

Fig. 1 | Phase $\mathbf{0} /$ microdosing regulatory framework from ICH M3 guidelines. Test compound exposure is defined on a continuum of doses and durations of exposure from a single microdose to the 14-day no observed adverse effect level (NOAEL). There is no therapeutic intent or intent to study tolerability. AUC, area under the concentration-time curve; $\mathrm{ICH}$, International Council for Harmonisation of Technical Requirements for Pharmaceuticals for Human Use. Adapted with permission from REF. ${ }^{141}$, Elsevier. 
Current drug discovery/development paradigm

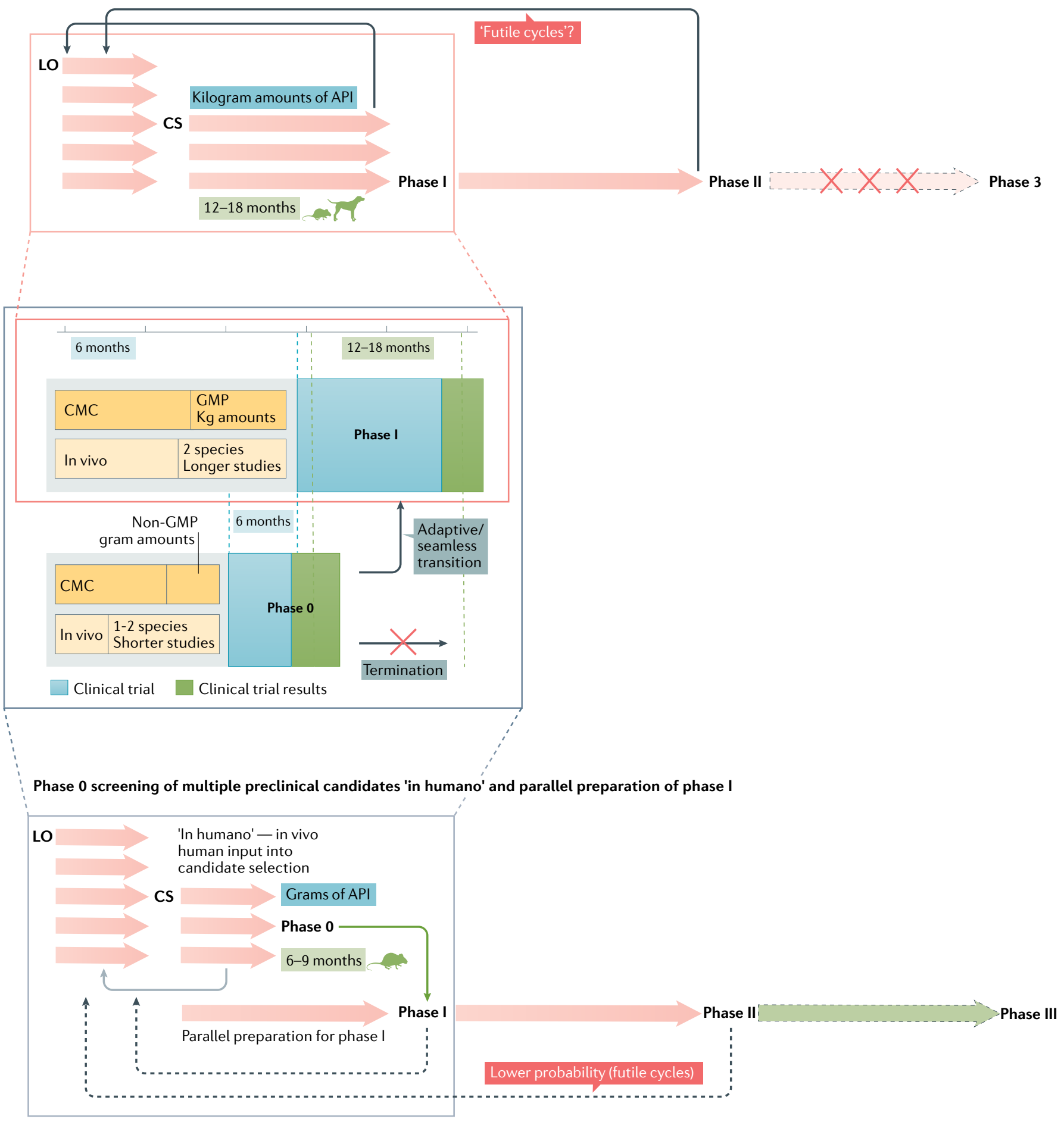

Fig. 2 | Phase $\mathbf{0}$ and phase I timelines. It is recommended that preparations for phase I continue in parallel with the conduct of the phase 0 study. This will allow a seamless transition to phase I or, alternatively, early termination of phase I on the basis of the phase 0 results. The costs of additional preclinical preparations, which might be lost in the event of termination of development, are minimal compared with the savings in time that such parallel development allows (see the main text). The contribution of in vivo human testing (that is, "in humano' ${ }^{\prime 3}$ ) to the selection of preclinical candidates is highlighted. This has the potential to reduce 'false negatives' (that is, the good drugs wrongly deselected on the basis of inappropriate animal or in vitro data) and also discover earlier, and therefore in a less expensive manner, those 'false positives' that may be discovered only at the end of expensive phase I studies in healthy volunteers or phase II studies in patients. Phase 0 approaches can provide human data for developmental decision 8-12 months before traditional phase I approaches. In the case of an adaptive phase $0 /$ phase I design, the phase 0 study application must be withdrawn before initiation of the phase I study (required by the FDA but not in the EU). The traditional drug development approach uses phase I as the first-in-human approach. The parallel phase 0/phase I approach is an adaptive design. API, active pharmaceutical ingredient; CMC, chemistry, manufacturing and controls; CS, candidate selection; GMP, good manufacturing practice; LO, lead optimization. 
Table 2 | Phase $\mathbf{0} /$ microdosing consortia and their primary objectives

\begin{tabular}{|c|c|c|}
\hline Consortium & Membership & Primary objective \\
\hline CREAM (published 2006) & $\begin{array}{l}\text { Xceleron, Schering; Institut de Recherches Internationales } \\
\text { Servier; F. Hoffmann-La Roche; Eli Lilly; Pharma Bio-Research } \\
\text { Group }\end{array}$ & $\begin{array}{l}\text { To compare the clinical pharmacokinetics of five drugs } \\
\text { - warfarin, ZK253 (Schering), diazepam, midazolam } \\
\text { and erythromycin - when administered at a } \\
\text { microdose or pharmacological dose }\end{array}$ \\
\hline EUMAPP (published 2011) & $\begin{array}{l}\text { Xceleron Ltd; Servier Group; Centre for Applied } \\
\text { Pharmacokinetic Research of the University of Manchester; } \\
\text { PRA International BV; Faculty of Pharmaceutical Sciences of the } \\
\text { University of Copenhagen; Pharmaceutical Research Institute } \\
\text { in Warsaw - funded by the EU }\end{array}$ & $\begin{array}{l}\text { To assess the ability of a microdose to predict } \\
\text { human pharmacokinetics following a therapeutic } \\
\text { dose of clarithromycin, sumatriptan, propafenone } \\
\text { acetaminophen and phenobarbital to explore the } \\
\text { source of any non-linearity }\end{array}$ \\
\hline $\begin{array}{l}\text { NEDO-MicroDosePJ } \\
\text { (published 2011) }\end{array}$ & $\begin{array}{l}\text { Association for Promoting Drug Development; University of } \\
\text { Tokyo; Setsunan University; RIKEN; Japanese National Institute } \\
\text { of Radiological Science; Sekisui Medical Co. Ltd; Pharm. } \\
\text { Industries Consortium }\end{array}$ & $\begin{array}{l}\text { To promote eIND studies in Japan; evolutional drug } \\
\text { development with the use of microdosing clinical trial }\end{array}$ \\
\hline PEDMIC (published 2014) & $\begin{array}{l}\text { Hull York Medical School (UK); Garner Consulting (UK); Institute } \\
\text { of Translational Medicine of the University of Liverpool (UK); } \\
\text { Alder Hey Children’s NHS Foundation Trust (UK); Good Clinical } \\
\text { Practice Alliance (Belgium); TNO Zeist (Netherlands); Tartu } \\
\text { University Hospital (Estonia); Pharmaceutical Research Institute }\end{array}$ & $\begin{array}{l}\text { To study developmental pharmacology in children } \\
\text { from } 0 \text { to } 6 \text { years of age by administering an oral } \\
\text { microtracer }\left(\left[{ }^{14} \mathrm{C}\right] \text { paracetamol or }\left[{ }^{14} \mathrm{C}\right] \text { midazolam) }\right. \\
\text { while the patient received the drug for therapeutic } \\
\text { reasons by intravenous administration }\end{array}$ \\
\hline $\begin{array}{l}\text { Phase-0/Microdosing } \\
\text { Network (2013 to present) }\end{array}$ & $\begin{array}{l}\text { A broad membership range, including pharmaceutical } \\
\text { companies, biotechnology companies, academia, the FDA, the } \\
\text { NIH, US Government national laboratories, patient advocacy } \\
\text { groups, contract research organizations and recognized } \\
\text { technical experts in AMS, PET, LC-MS and CRDS }\end{array}$ & $\begin{array}{l}\text { To use the collective interdisciplinary knowledge } \\
\text { and skills of a consortium of drug development } \\
\text { stakeholders who share interest in the potential } \\
\text { of phase } 0 \text { including microdosing approaches to } \\
\text { increase the efficiency and productivity of drug } \\
\text { development }\end{array}$ \\
\hline
\end{tabular}

AMS, accelerator mass spectrometry; CRDS, cavity ring-down spectroscopy; CREAM, Consortium for Resourcing and Evaluating AMS Microdosing; eIND, exploratory investigational new drug: EUMAPP, European Microdosing Partnership Programme; LC-MS, liquid chromatography-mass spectrometry; NEDO-MicroDosePJ, the Japanese New Energy and Industrial Technology Development Organization Microdose Project; PAMPERS, Paediatric Accelerator Mass Spectrometry Evaluation Research Study; PEDMIC, Pediatric Microdosing: Elucidating Age-Related Changes in Oral Absorption To Guide Dosing of New Formulations; PET, positron emission tomography.

of dynamic scenarios of concentrationtime profiles at various sites within the body may be simulated with this powerful mechanistic method, each conditioned on the particular compound and setting of interest, such as single or multiple doses and oral or parenteral administration ${ }^{153,154}$. In its simplest form, one often desired global metric is prediction of the systemic exposure (area under the pharmacologically active unbound concentration-time profile at the steady state). The fundamental relationship between dose-normalized exposure of an orally administered drug and intrinsic metabolic and transportermediated clearance via saturable and nonsaturable processes has been described (FIG. 4; Supplementary information B). If the anticipated therapeutic concentrations are below $K_{\mathrm{m}}$ (Michaelis-Menten constant) of any of the processes, linear kinetics are expected to prevail and drug exposure time profiles can be successfully predicted by the proportional extrapolation from a microdose to the therapeutic dose. However, deviations from linearity are expected at higher concentrations, which can be predicted from a combination of physicochemical and human in vitro data, complemented by phase 0 microdose data within a PBPK modelling framework (FIG. 4; Supplementary information B). Greater confidence in this approach would transpire if in vitro data coupled with microdose data in a preclinical species predict in vivo non-linear pharmacokinetics data in the same species.

Even though considerable progress has been made recently in predicting human pharmacokinetics using PBPK modelling and other preclinical methods, much of the drug-related inputs are generated from in vitro or in silico data, which often bring considerable uncertainty in the extrapolation to humans. This is especially so when one is dealing with novel or poorly understood enzymes and transporters, as may be the case with the ever-increasing developmental emphasis on drugs, targets and mechanisms that are uniquely relevant in humans.

Impact of TMDD. TMDD in small molecules is a much less common cause of pharmacokinetic non-linearity than saturation of metabolism or transporter-mediated processes, involving compounds that have a restrictive nonspecific distribution in tissues and an exquisitely high affinity for their target. However, failure to take TMDD into account can lead to serious errors in prediction of phase I pharmacokinetic data. That said, TMDD is widely recognized as typical of monoclonal antibodies, in which engagement with the minute amounts of endogenous antigen leads to accelerated elimination, thereby increasing total clearance and resulting in a shorter half-life at low doses. However, in recent years, attention has also been drawn to small-molecule drugs ${ }^{155-157}$, although TMDD was already identified with warfarin and bosentan many years ago ${ }^{158,159}$. Compared with biologics, the reason why TMDD is less likely among small-molecule drugs is because their distribution in the body tends to be much less confined (due to high-capacity non-specific tissue distribution, especially for basic and neutral lipophilic compounds).

TMDD has been regarded mostly as a confounding variable in extrapolating drug exposures from a microdose to therapeutic 
doses. For drugs with potential for TMDD, a microdosing study can, however, offer valuable information to verify the impact of target binding in humans. The resulting pharmacokinetic profile can be used to assess the degree of discrepancy from prediction by PBPK modelling and simulation based on physiological and biochemical variables (for example, with and without target considerations), obtained from in vitro assays of target binding, and a combination of physicochemical and in vitro ADME studies to predict the non-target human pharmacokinetics. With most targets located in tissues rather than in the circulation, the impact of target engagement (TMDD) on pharmacokinetics is to increase both the volume of distribution and the elimination half-life when compared with the non-target engagement state. If the observed data at a microdose can be captured with reasonable accuracy by PBPK modelling with target consideration, validation may be performed in one or two preclinical animal species known to also express the target. If knockout models lacking the target are available, the comparative results between the knockout and wild-type animals would provide direct evidence of the impact of the target engagement on pharmacokinetics.

Alternatively, experiments can be performed to obtain the systemic pharmacokinetics over a range of doses (from a microdose to further escalating doses, but still within the phase 0 framework; see FIG. 1 and TABLE 1) and in vitro target binding parameters, followed by PBPK modelling-based simulation of systemic pharmacokinetic profiles at various doses given to the preclinical animals. Success at this stage gives credence to a similar modelling-based analysis providing a priori prediction of pharmacokinetic profiles in humans receiving various doses to limit surprises on moving to the more costly phase I trials (see Supplementary information $\mathrm{C}$ for further details of TMDD considerations with phase 0 approaches).

\section{Advantages of phase 0 approaches}

Phase 0 approaches can increase the quality of drugs entering clinical development by allowing preclinical candidate selection to be based on in vivo human data ${ }^{97,100}$ (BOX 2). This could presumably lead to reduced attrition in later phases of development. And since this could be done with fewer resources than traditional phase I approaches (for example, by leading to earlier termination of non-viable compounds), it could also increase the number of drugs that could enter clinical development ${ }^{2,6,139,160}$. Phase 0 approaches could also increase the value of the patent life of back-up compounds by bringing forward developmental decisions and making those decisions cheaper to arrive at. A 2016 analysis found the increase in value of a successful back-up compound - one that can enter clinical development 8 months earlier owing to quicker elimination of a non-viable lead candidate in phase 0 rather than phase I - to be worth approximately US\$300 million ${ }^{139}$ (FIG. 2). Possibly most compelling are recent applications of phase 0 approaches by industry and academia in actual drug development, suggesting that in certain developmental scenarios, these approaches provide de facto solutions that override traditional options (TABLE 3).

Table 3 | Applications of phase 0 approaches

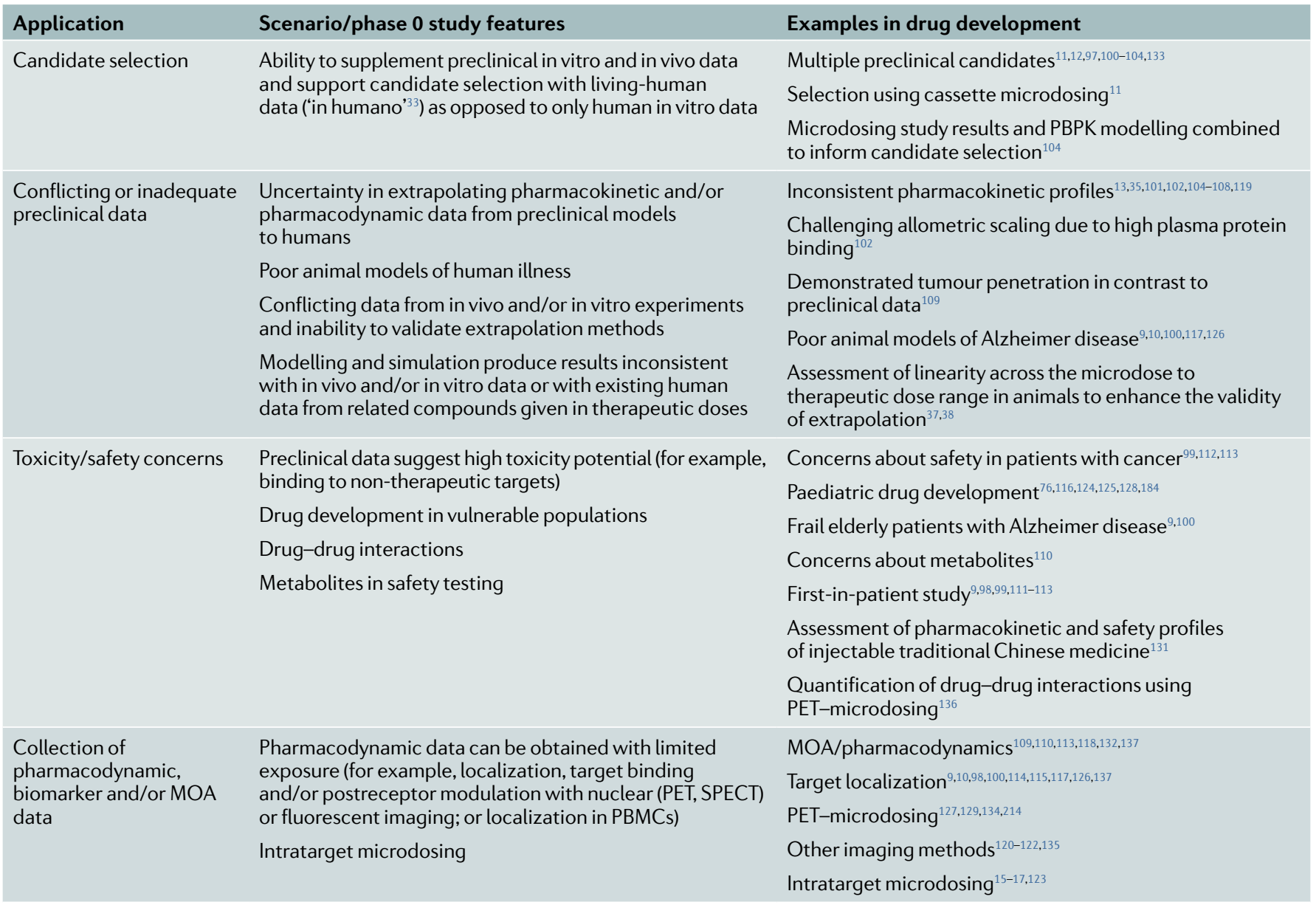

MOA, mechanism of action; PET, positron emission tomography; PBMCs, peripheral blood mononuclear cells; PBPK, physiologically based pharmacokinetic; SPECT, single-photon emission computed tomography. 
Box 1 Analytical tools used in phase $\mathbf{0} /$ microdosing studies

The subtherapeutic exposures used in phase 0 approaches often necessitate sensitive analytical techniques to detect the test compound in body tissues. Those used most commonly in phase 0 studies are listed below (see also Supplementary information $\mathrm{A}$ ).

\section{Liquid chromatography-tandem mass spectrometry}

A sensitive analytical technique that combines the separating power of liquid chromatography with the highly sensitive and selective mass analysis capability of mass spectrometry ${ }^{57,58,206}$. Unlike accelerator mass spectrometry (AMS), which is a universal detector of drug-related material (assuming the ${ }^{14} \mathrm{C}$ label remains incorporated in the analyte), liquid chromatography-tandem mass spectrometry (LC-MS/MS) generates data specific to the analytes that are monitored (usually the parent drug and sometimes metabolites).

\section{Accelerator mass spectrometry}

An extremely sensitive nuclear physics technique for the measurement of the ratios of rare to abundant isotopes (for example ${ }^{14} \mathrm{C} /{ }^{12} \mathrm{C}$ ) $19,149,207-209$. The sensitivity of AMS has facilitated study designs by which tiny quantities of a drug can be administered, and drug-related material can be measured in ex vivo samples, such as blood or other tissues, to define the absorption, distribution, metabolism and excretion (ADME) properties of the drug.

\section{Positron emission tomography}

A nuclear medicine imaging technique that produces non-invasive, high spatial/temporal resolution, dynamic images of the test compound or its targets ${ }^{21,139,147,210-212}$. Positron emission tomography (PET) systems detect pairs of $\gamma$-rays emitted indirectly by a positron-emitting radionuclide at $180^{\circ}$ to each other. Three-dimensional images of the tracer distribution within the body are then constructed by computer analysis. In drug development ${ }^{11} \mathrm{C}$ (half-life $20.4 \mathrm{~min}$ ), ${ }^{18} \mathrm{~F}$ (half-life $109.8 \mathrm{~min}$ ), ${ }^{89} \mathrm{Zr}$ (half-life 3.3 days) and ${ }^{124}$ I (half-life 4.2 days) are commonly used as PET radionuclides. In modern $\mathrm{PET}$-computed tomography (CT) scanners, PET combined with CT scan is performed on the patient during the same session, in the same machine. PET can be used to study drug disposition, when the drug is radiolabelled with a PET radionuclide and administered at microdoses, or to study biomarkers of drug effects (for example, target binding, receptor occupancy and postreceptor modulation).

The main characteristic of phase 0 approaches is the increased safety versus traditional first-in-human studies $^{27,30-33,36,139,147,151,161,162}$. The increased safety can have a profound impact on the process of clinical development, leading to reduced regulatory requirements, which potentially means quicker and cheaper testing in humans, with results available 8-12 months earlier than achieved with traditional phase I studies ${ }^{33,139}$ (FIC. 2). The main benefits include triaging multiple preclinical candidates with living human data, and terminating non-viable candidates more quickly and with less investment (that is, 'fast-fail', 'fail-cheap' or 'truth-seeking' approaches) $)^{163-165}$.

A common misconception about phase 0 approaches is that they are inferior to the gold standard of phase I studies. While phase I

\section{Near-infrared fluorescent imaging}

An optical imaging technique that can be used to image a wide variety of molecular entities in vivo through the promise of versatile fluorescent probe design ${ }^{120,121}$. The use of near-infrared wavelengths for imaging enables relatively deep photon penetration into tissue, minimal tissue autofluorescence, less scatter and higher optical contrast when exogenous near-infrared fluorophores are introduced.

Each of the techniques has advantages and disadvantages associated with it, which need to be considered in the context of the study design and desired end points. As shown in the figure, AMS is generally the most mass-sensitive technique and, as with LC-MS/MS, is used for the analysis of ex vivo samples, whereas PET provides in vivo assessments (temporally limited by the radioactive decay half-life of the radionuclide used). Both PET and AMS require the presence of radiolabelled material in the dose, whereas LC-MS/MS does not but has much wider availability, with the lowest associated overall study and analytical costs. Of course, combinations of the techniques can be, and have been, used in phase 0 studies. Combining PET-microdosing with highly-sensitive AMS and/or LC-MS/MS can overcome some of the limitations of PET-microdosing by providing longer-term systemic pharmacokinetic data correlated with tissue-specific and target-compartment-specific data ${ }^{19,47}$. Such complementary and synergistic PET/AMS/LC-MS/MS data can inform physiologically based pharmacokinetic models used in extrapolation of microdose data to therapeutic-level exposures to improve the predictability of therapeutic-level exposures ${ }^{213}$.

The figure provides a qualitative comparison of the utility of the main features of the three technologies that are most applied for phase 0 and microdosing studies.

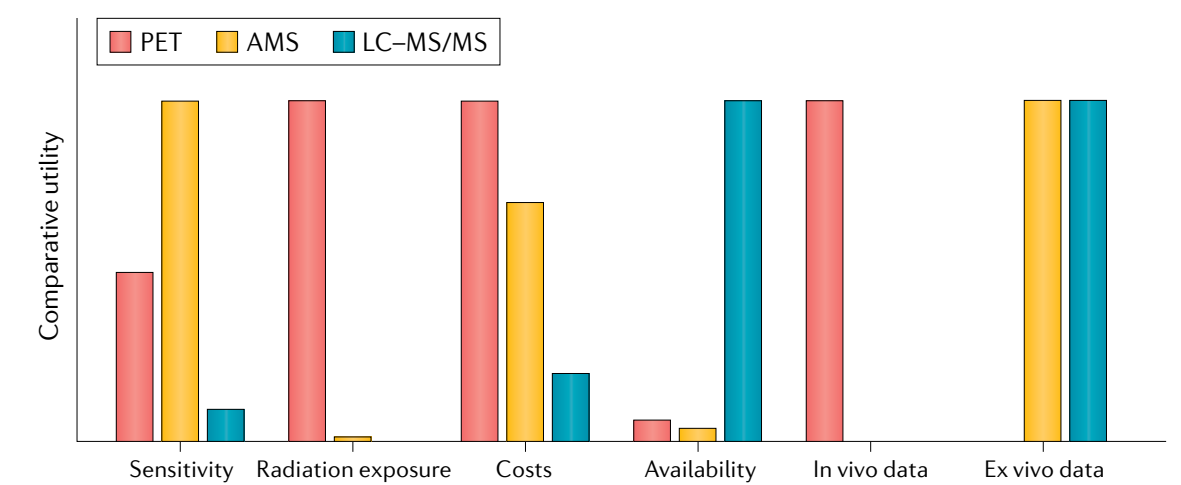

studies can administer the full range of therapeutic doses and therefore obviate the need for extrapolation, phase 0 approaches offer several methodological advantages over traditional approaches. The increased safety means that populations usually excluded from first-in-human studies can be tested earlier. Importantly, phase 0 enables first-in-human studies to be conducted directly in patients (see later) and therefore test compounds not only in their intended targets and clinical presentations but also in the stage of development that has the highest attrition rates, and possibly $2-2.5$ years earlier than traditional approaches ${ }^{2,5,166,167}$. It is obviously of value to obtain, as soon as possible, data in the stage most likely to lead to termination of development. Other methodological advantages over phase I approaches discussed later are the ability to test multiple candidates simultaneously in the same individuals (cassette microdosing), the ability to test enteric drugs by administering them parenterally and the use of methods such as ITM ${ }^{11,13,16,28}$.

\section{First-in-patient studies}

The highest attrition in clinical development is in the first-in-patient stage, typically phase Ib or phase IIa, being up to twice as high as in phase Ia or phase III (REFS ${ }^{2,5,166-168}$ ). This is perhaps no surprise as it is in such trials that the first real test of translation is typically undertaken: testing whether the drug arrives at its intended tissue/organ, establishes adequate dynamic concentrations in the target, binds to the intended molecular target and initiates specific pharmacological modulations consistent with the intended therapeutic effects ${ }^{169}$. Hence, it is critical 


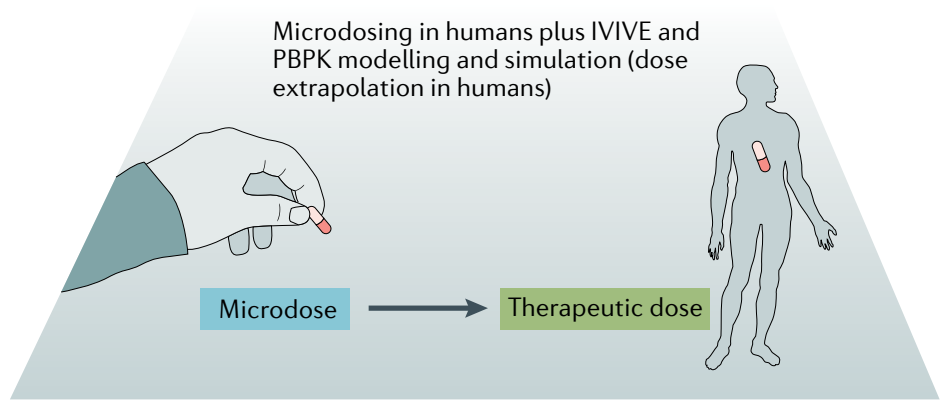

\section{Key questions}

- Is there non-linearity in the microdose versus therapeutic-level exposure range?

What mechanisms are responsible for the non-linearity?

- Can we predict the impact of the non-linear mechanisms in humans?

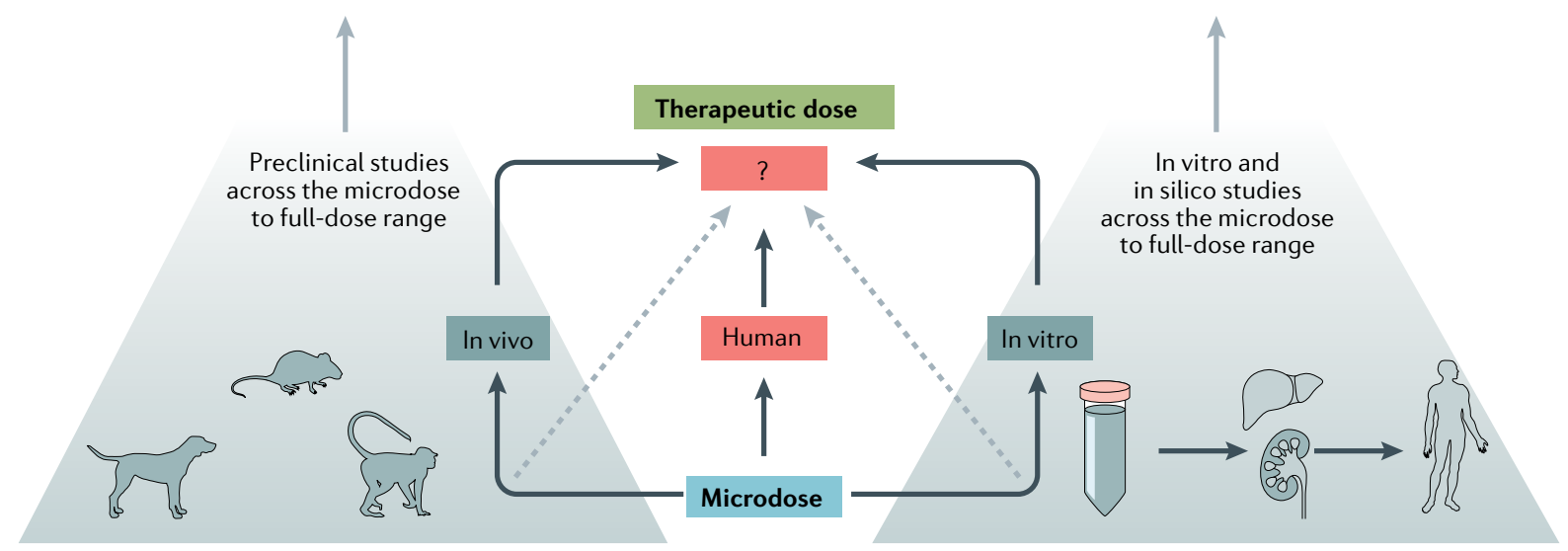

Fig. 3 | Extrapolation of subtherapeutic phase 0 data to therapeuticlevel exposures. Preclinical in vitro/in vivo studies and modelling/ simulations can be applied to predict saturability of non-linear processes. In vitro data can be extrapolated, first from a microdose to therapeutic doses and then from in vitro studies to human studies (and together, summarized by the dotted line). In vivo data can also be extrapolated, first from a microdose to therapeutic doses, and then from in vivo studies to human studies (and together, summarized by the dotted line). Both the in vitro data and in vivo data are then modelled and contribute to prediction of extrapolation from a human microdose to human therapeutic doses. IVIVE, in vitro to in vivo extrapolation; PBPK, physiologically based pharmacokinetic. to be able to obtain such information as early as possible. First-in-patient trials can be done with phase 0 approaches as the first-in-human studies, allowing collection of pharmacodynamic, biomarker and MOA data in the molecular, tissue and population $\operatorname{targets}^{15,16,28,34}$. If a first-in-patient phase 0 study leads to termination of a non-viable candidate, it will do so up to 2.5 years before traditional approaches.

The importance of de-risking candidates early in the increasingly expensive clinical development process has been emphasized recently ${ }^{2,4}$. Indeed, industrial and academic drug developers have taken advantage of this opportunity, explicitly encouraged by regulators (see TABLE 3 and ICH M3 guidance Section 7) ${ }^{25,98,99,111-113}$. One of the main reasons to exclude patients from first-in-human studies - that they are too vulnerable to the potential risks of exposure to novel drugs without prior in vivo human data - is addressed with the inherent safety of phase 0 approaches. The concern about drug-drug interactions (DDIs) with concomitantly administered drugs can also be minimized with phase 0 approaches. With microdosing, the low exposure to the test drugs will not act as a perpetrator of DDIs with the concomitant drugs administered at therapeutic doses, and although the novel drugs could be DDI victims of the concomitant drugs, at microdose levels they are unlikely to pose any risk and can provide a safe setting for the study of any potential DDIs.

\section{Cassette microdosing}

Cassette microdosing is a method to assess drug disposition, including the potential for DDI (as 'victims' only), of multiple compounds administered simultaneously at microdose levels to research participants. Cassette microdosing can considerably reduce the variability, complexity, and costs of first-in-human studies ${ }^{11,54,55,61,68,170,171}$. Advances in liquid chromatography-tandem mass spectrometry technology, which nowadays offers high and ever-increasing sensitivity and resolution of test compounds and their metabolites in biological fluids, have considerably expanded the applications of cassette microdosing ${ }^{58}$.

The methodological advantage of the cassette microdosing approach stems from the fact that the drugs are given simultaneously at doses that are far below their pharmacologically active threshold (at $1 / 100$ or less of it; that is, a microdose), and so are unlikely to interact with each other ${ }^{46}$. The total cumulative dose of the compounds should not exceed a single microdose, or $100 \mu \mathrm{g}$ for approach 1 in the ICH M3 guidance (TABLE 1). The design provides a controlled and minimally variable environment in which to study the relative effects of biological elements (for example, enzymes, transporters and genomics) or other xenobiotics (for example, reference perpetrator probes in DDIs) on multiple test compounds ${ }^{50,54,55}$. This may be an optimal research setting using human in vivo data to select among multiple preclinical candidates in a highly controlled environment ${ }^{55}$.

Multiple research projects have validated and expanded the application of cassette microdosing ${ }^{11,12,46,54,57,61,68,96,172-174}$. Importantly, one study applied cassette microdosing in a real-life drug development scenario of a resource-limited academic setting, and used bioavailability, total body clearance and volume of distribution for the selection of the lead candidate among two novel aromatase inhibitors ${ }^{11}$ (TABLE 3). Another research project combined cassette microdosing with ITM (see later) by implanting a device into solid tumours that 
releases multiple microdoses of different test drugs to test for chemoresistance ${ }^{16}$.

\section{Parenteral administration}

Although most drug development is for enterally administered drugs (for example, orally), parenterally (for example, intravenously) obtained definitive pharmacokinetic parameters, especially clearance, absolute bioavailability and volume of distribution, are very useful in the characterization of the compound ${ }^{175}$. As noted earlier, study of drug parameters after intravenous microdose administration is attractive because it has been associated with very high probability of success in extrapolating from a microdose to the therapeutic dose ( $94 \%$ of cases are within a twofold range $)^{30,36}$. This may be an especially useful prospect when preclinical oral administration raises concerns about linearity of extrapolation due to first-pass effects of transporters or metabolism ${ }^{13,30,36}$. Parenteral administration is possible in a microdose for almost all drug candidates even if their intended therapeutic route of administration is enteral. This is routinely done in absolute bioavailability (microtracer) studies, where the therapeutic-level dose is administered orally and the isotopically labelled tracer dose (effectively a microdose-level exposure) is administered intravenously. An important advantage of phase 0 studies, however, is that the microdose can be administered intravenously while the therapeutic-level dose is not yet approved for human testing. This has been applied in novel drug development ${ }^{13,14,41}$ (TABLE 3). Finally, the equivalent of a phase I absolute bioavailability (microtracer) study can be accomplished as a microdose study, for example, by giving the enteral dose at $99 \mu \mathrm{g}$ with the ${ }^{14} \mathrm{C}$-labelled parenteral dose at $1 \mu \mathrm{g}$ to comply with the total $100-\mu$ g microdose limit (or the equivalent threshold definition).

\section{Intratarget microdosing}

In ITM, a microdose is administered into a physical target that is $1 / 100$ or less of the total body mass, briefly generating local therapeutic-level exposures in the target(s) of interest, and in parallel generating longer-term systemic microdose exposures. For example, if a microdose that is $1 / 100$ of the therapeutic-level dose is administered into the radial artery, then the hand, which is about $1 / 100$ of the total body mass, will be exposed momentarily to therapeutic-level concentrations (FIG. 5). ITM can then be used to obtain pharmacodynamic, biomarker and MOA data in the target tissues/compartments, and simultaneous systemic microdose data from the rest of the body, for incorporation into models of the microdose to therapeutic dose range. A particularly attractive aspect of ITM is the possibility of comparing symmetrical organs (for example, hands, kidneys and brain hemispheres), whereby one receives the ITM intervention and therefore therapeutic-level exposure while the other is exposed to a systemic microdose, allowing testing across the microdosetherapeutic-level exposures in real time in the same individuals $\mathrm{s}^{28,66,70}$.

A proof-of-concept human ITM study used insulin administered into the radial artery to demonstrate the feasibility of obtaining pharmacodynamic and MOA data (glucose plasma levels and $\left[{ }^{18} \mathrm{~F}\right]$ fluorodeoxyglucose uptake into muscle tissue) in the ipsilateral hand ${ }^{70}$. The study also demonstrated the utility of control and simultaneous contralateral systemic microdose-level measurements in modelling the microdose versus therapeutic-level dose range. Recent reports applied ITM principles in the development of TRPV 1 antagonists for pain management by using microdose amounts to elicit pain sensations and behaviour in skin nociceptors in a limited area of $\operatorname{skin}^{17}$, and or simultaneously testing multiple candidates (cassette microdosing) for chemoresistance by administering them directly into tumours ${ }^{15,16,18}$. Advanced modelling techniques using physiologically based pharmacokinetics and pharmacodynamic principles, including, where appropriate, in vivo/in vitro modelling of molecular (for example, receptor binding) and tissue (for example, tissue concentrations and transporters) markers of test compound engagement, are being

\section{Box 2 | Potential advantages and disadvantages of phase 0 approaches}

\section{Potential methodological advantages (with references from application in novel drug}

development)

Utility of first-in-patient testing. All phase 0 studies can be conducted directly in patients as the first-in-human study potentially saving $2-2.5$ years in comparison with the traditional drug development approach, which introduces first-in-patient testing only in phase lb or phase Ila $a^{9,10,98,99,111-113}$.

Utility of intravenous drug administration. Most orally administered drugs can be administered parenterally in a microdose. Parenterally (for example, intravenously) obtained definitive pharmacokinetic parameters, especially clearance, absolute bioavailability and volume of distribution, are very useful in the characterization of the compound ${ }^{13,14,41}$.

Utility of the cassette microdosing approach. Simultaneous administration of multiple drugs in a microdose is possible because of the negligible impact of interactions between them. It allows a considerable reduction in the variability of human studies and associated time and resources spent on clinical trials ${ }^{11,12}$.

Utility of intratarget microdosing (ITM). Microdose calculated on total body basis is administered into a target that is less than $1 / 100$ th of the body mass. This results in therapeutic-level exposure at the target and a systemic microdose exposure.

Potential logistic advantages (with references from application in novel drug development) Phase $0 /$ phase I adaptive design. Application of an adaptive design allows the seamless transition from phase 0 to phase I with preparation for phase I continuing in parallel with the conduct of the phase 0 study $^{10,14,35,111,137}$.

Limited resources. Phase 0 approaches have been applied by drug development entities that have limited resources and thus are unable to enter into full phase I development programmes (for example, academic entities and small biotechnology companies). For such entities the availability of human data from the phase 0 studies is an attractive way to increase the value of the test compound $d^{11,12,99,100,107,108,111-113,119}$.

Multiple candidates under a single investigational new drug application. Exploratory clinical trials with multiple drugs (for example, cassette microdosing) can be submitted for regulatory approval under a single investigational new drug application ${ }^{100,108}$.

Potential disadvantages

Extrapolation concerns. When uncertainty about extrapolation from microdose to therapeuticlevel exposures cannot be mitigated with use of preclinical data and modelling and simulation.

Challenging radiolabelling.

Challenging validation of analytical standards.

Delays to phase I timelines. When phase 0 methodological or logistical challenges lead to significant delays to phase I timelines, a dedicated analysis of the potential value of the phase 0 data should be conducted to determine whether the delays are acceptable. 
developed. They will enhance the simulation of tissue exposure and the extrapolation of time-limited and local ITM data to continuous, therapeutic-level systemic exposures $^{176}$.

Adaptive phase 0/phase I study design In an adaptive phase $0 /$ phase I design, the two studies are planned prospectively so that the complex preparations for phase I can be performed in parallel with the conduct of a
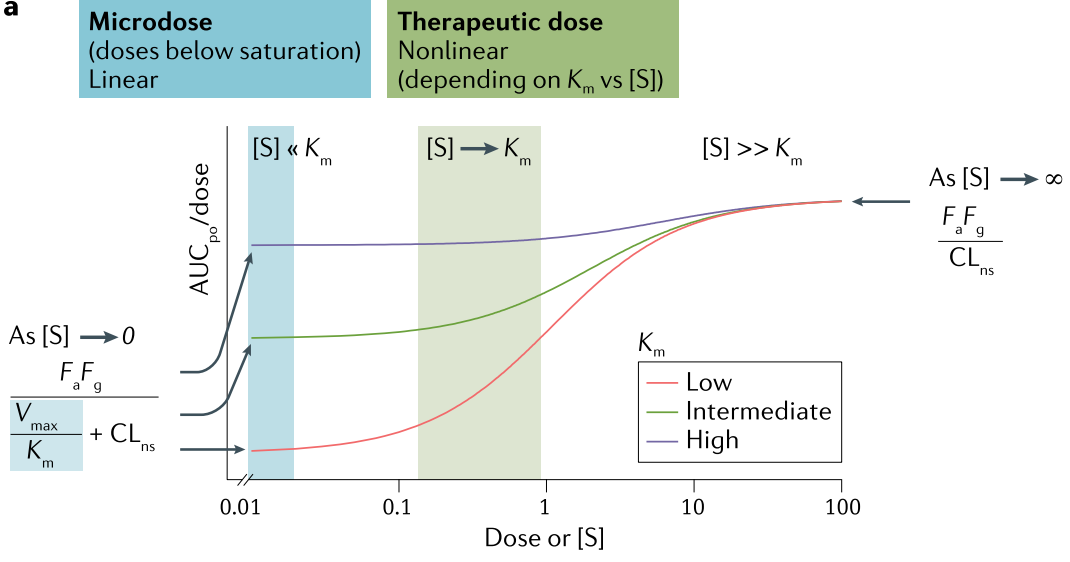

b 'Bottom-up' prediction of human PK

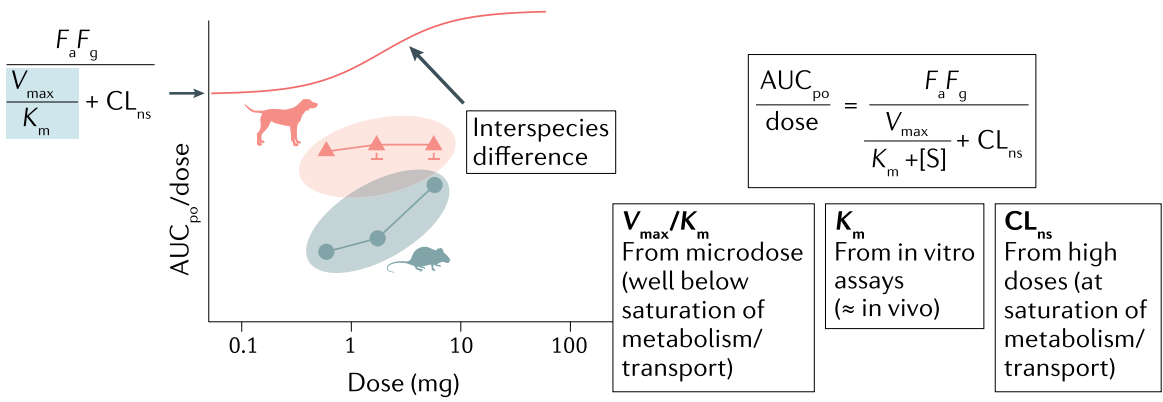

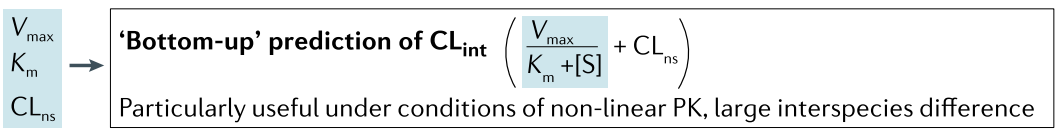

Fig. 4 | Extrapolation from microdose to therapeutic-level exposures - role of PBPK modelling. Physiologically based pharmacokinetic (PBPK) models can be characterized as a 'bottom-up' approach when biochemical parameters obtained in vitro predict in vivo pharmacokinetics (PK) (also called in vitro to in vivo extrapolation), a 'top-down' approach when in vivo data are used to obtain biochemical parameters or a hybrid and practical 'middle-out' approach. PBPK modelling can explore various scenarios by generating concentration-time profiles in plasma and tissues. A more restrictive situation, prediction of the area under the unbound concentration-time profile (AUC), is considered here for illustrative purposes. a | The figure and the following equation indicate the fundamental relationship between dose-normalized exposure to an orally administered drug ( $A \cup C_{\mathrm{po}} /$ dose) and intrinsic clearance $\left(\mathrm{CL}_{\text {int,all }}\right)$ via saturable and non-saturable processes ${ }^{153,154}$ : $A U C_{p o} /$ dose $=F_{a} F_{g} / C_{\text {int , all }}=F_{a} F_{g} / \frac{V_{\max }}{K_{m}[S]}+C_{n s}$, where $F_{a} F_{g}, C L_{n s}, K_{m}, V_{\text {max }}$ and [S] represent the fraction absorbed into the portal vein $\left(F_{\mathrm{a}}\right.$ is the fraction of the oral dose entering the intestinal wall and $F_{g}$ is the fraction escaping loss in the gut wall), the intrinsic clearance via non-saturable processes, the Michaelis-Menten constant, the maximum elimination velocity and the concentration of the unbound drug substrate $\mathrm{S}$, respectively. $\mathbf{b} \mid$ Microdosing can provide information to aid in accurate prediction of the intrinsic clearance $\left(V_{\max } / K_{m}\right)$ for saturable processes, and thereby drug exposure in humans, even under conditions of nonlinear PK and substantial interspecies differences. In a simple example where the fraction absorbed in the intestine $\left(F_{a} F_{g}\right)$ is independent of the dose and where therapeutic doses yield drug exposure well below $K_{m}$, linear kinetics are expected to prevail and drug exposure can be successfully predicted by proportional extrapolation from a microdose to the therapeutic dose; not only $A \cup C_{p o} /$ dose $=F_{a} F_{g} /\left(\frac{V_{\max }}{K}+C_{n n}\right)$ but also the plasma concentration-time profile. Having ascertained the $V_{\max } / K_{m}$ ratios from a microdose clinical study and using the $K_{m}$ value from relevant in vitro experiments, one can individually identify and incorporate both $K_{m}$ and $V_{\text {max }}$ into PBPK modelling, which in turn predicts dose-dependent changes in the blood drug exposure (AUC $C_{p o}$ ). This 'bottom-up' prediction of the intrinsic clearance can be particularly useful when drug exposure in humans cannot be extrapolated from preclinical species because of interspecies differences ${ }^{204,205}$. the phase 0 trial. Results from the phase 0 trial can then lead to termination of the phase I programme before recruitment begins (FIG. 2). The approach is feasible and effective, and has been applied in novel drug development (TABLE 3), allowing seamless transition from phase 0 to phase I without the cost of delaying initiation of phase I while maintaining the potential for the considerable benefit of early termination if the results of the phase 0 study indicate the drug is non-viable ${ }^{35,111}$ (FIG. 2). The phase 0/phase I design may also offer an attractive option for patients who are looking to volunteer for research studies with therapeutic potential (since the phase 0 component has no therapeutic potential in itself). Another advantage of the adaptive design approach is that should the decision to proceed with development be undertaken, the design of the phase I component could be improved by the knowledge obtained in the phase 0 component, such as estimation of the therapeutic dose, utility of biomarker and proxy end points, and identification and characterization of TMDD. The phase 0 regulatory eIND application must be withdrawn before initiation of the phase I component in the USA, but not in the EU.

\section{Phase 0 applications}

Phase 0 approaches have already demonstrated value in several drug development scenarios (TABLE 3). These include triaging preclinical candidates when there are multiple undifferentiated candidates, when preclinical sources are conflicting or ambiguous, when the therapeutic index is narrow (for example, in the paediatric population) and when pharmacodynamic, biomarker and MOA data can be obtained ${ }^{9,16,70,97,140}$.

\section{Candidate selection}

In many developmental scenarios, multiple structural analogues of the test compound, or compounds targeting the same molecular target, reach the end of the discovery stage without sufficient information to meaningfully differentiate between them. Since only one (the 'lead candidate') usually proceeds to the resource-intensive and expensive clinical development, it must be selected from other candidates/analogues on the basis of available preclinical data, including in silico, in vitro (animal and human) and animal in vivo data. Phase 0 approaches can add human in vivo data to the selection process, perhaps most attractively by using cassette microdosing, in which multiple analogues can be 


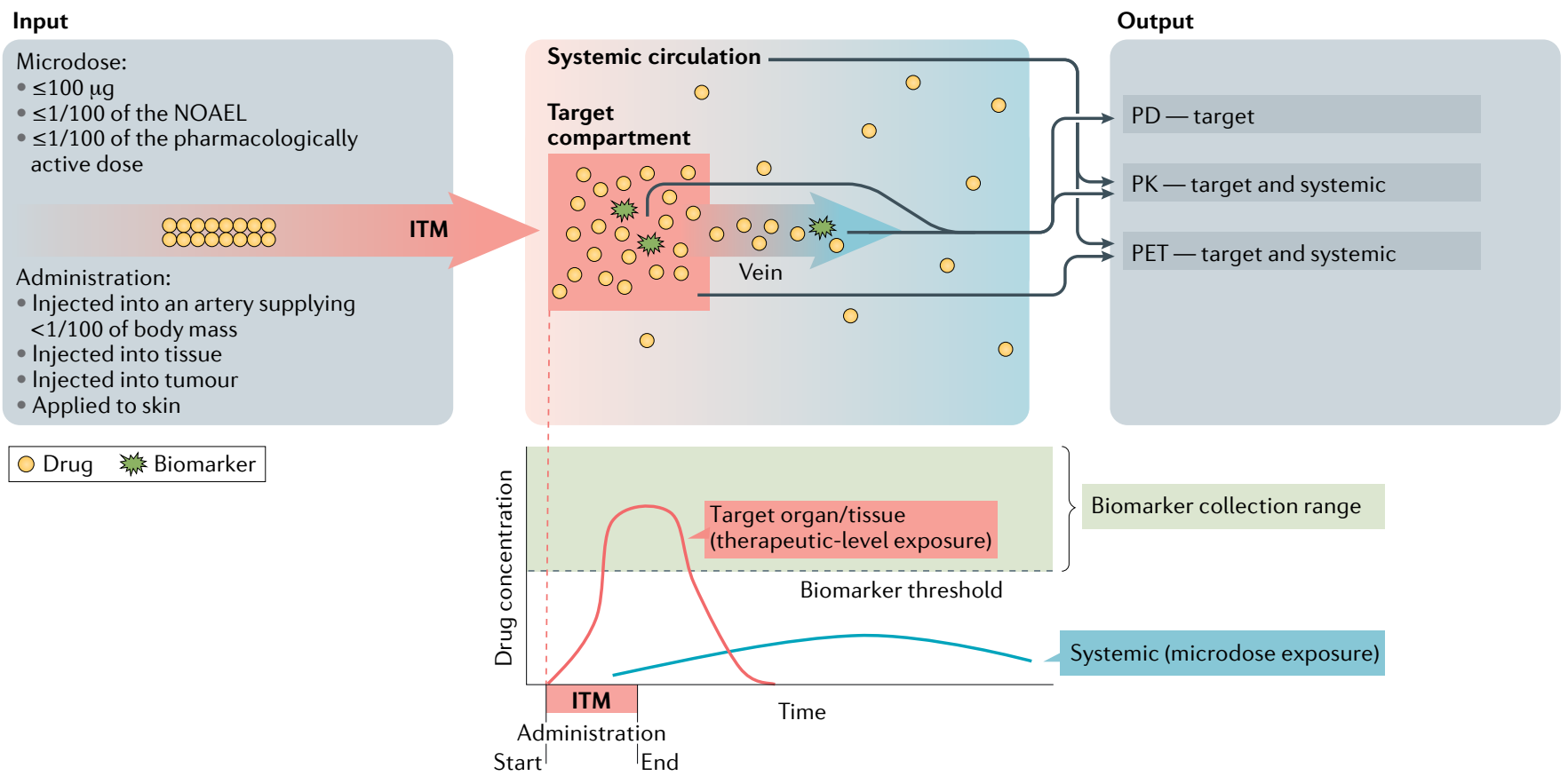

Fig. 5 | Intratarget microdosing (ITM) $)^{28,66,70}$. With use of an intra-arterial administration method, administration of a microdose (100 $\mu$ g or less, or pharmacologically active dose or 1/100 of the no observed adverse effect level (NOAEL)) temporarily surpasses the therapeutic-level exposure in a small target (1/100 or less of the body mass) and may allow collection of pharmacodynamic, biomarker and mechanism of action data, as well as systemic microdose pharmacokinetics (PK). PD, pharmacodynamics; PET, positron emission tomography.

administered simultaneously to the same research participants, and can also be submitted together in one regulatory package, making for an efficient and streamlined programme ${ }^{33}$.

This application has been used in novel drug development (TABLE 3) and is most appropriate when the candidates are not sufficiently differentiable on the basis of preclinical data alone $\mathrm{e}^{11,12,97,100-104,133}$. The first such application used microdoses of three preclinical analogues and therapeutic doses of two structurally similar $\mathrm{H}_{1}$ antagonist analogues, administered orally and intravenously, to characterize pharmacokinetic profiles where preclinical data were unable to separate the candidates ${ }^{97}$. Specifically, for these anti-insomnia compounds, the shape of the concentrationtime curve was critical for effective compound selection. The microdose study was able to identify the candidate with the best bioavailability profile (suggesting rapid sleep onset), shortest half-life (suggesting low incidence of next-day drowsiness) and lowest variability (suggesting greater predictability of therapeutic effect). In addition, because two of the five structurally related analogues had been previously tested in humans in therapeutic doses, there was little uncertainty about the validity of the extrapolation from microdoses to therapeutic doses for the novel compounds.
A more recent study used microdose study pharmacokinetic results, in vitro ADME data and PBPK modelling to inform candidate selection between four Nav1.7 sodium channel inhibitors developed for pain treatment ${ }^{104}$. These examples illustrate the potential of phase 0 for low-cost and effective triaging of compounds with multiple undifferentiable preclinical candidates, but most importantly the potential to increase the quality of drugs entering clinical development by using human in vivo data in their selection.

\section{Conflicting or inadequate preclinical data}

It is often the case that pharmacokinetic data generated from one animal species conflict with data generated from another, or there may be inconsistencies between in vivo, in vitro and/or in silico models, which leads to poor confidence for moving candidates into clinical development ${ }^{13,101,104-108}$. In other cases, there are simply no adequate in vivo/ in vitro/in silico models of human disease, the therapeutic targets and/or test compound $\mathrm{MOA}$, to adequately inform candidate selection. Such is often the case with central nervous system (CNS) preclinical models for depression, schizophrenia, Alzheimer disease and indeed for passage across the blood-brain barrier into the CNS from the systemic circulation ${ }^{9,100,109,117,177}$. As drug development becomes more 'human specific' recognizing that 'human is the best model for human' and development capitalizes on uniquely human genomic and other systems biology information, the value of phase 0 to supply not only healthy volunteer data but also patient data may become invaluable for candidate selection ${ }^{35}$.

The first such application used a PETmicrodosing study to select between four ${ }^{18} \mathrm{~F}$-labelled candidates as amyloid imaging agents $^{100}$, owing to the lack of adequate preclinical models of Alzheimer disease and amyloid deposits in the human brain. The compound that showed the best amyloid imaging separation between healthy volunteers and patients with Alzheimer disease and had the best pharmacokinetic and pharmacodynamic parameters was selected for continued development and eventually received regulatory marketing approval. In 2010, a microdose study was used to select from three candidates among a novel benzopyran class of selective cyclooxygenase 2 inhibitors on the basis of half-life ${ }^{102}$. Allometric scaling had been unreliable in this class of highly plasma protein-bound compounds. Another microdosing study investigated the antimalarial drug candidate GSK3191607, which demonstrated conflicting preclinical data from the animal models used to estimate human pharmacokinetics (mouse, rat and $\operatorname{dog})^{13}$. This was the first study 
using an intravenous microdose of an oral drug whose results led to termination of development. More recently, a microdosing study was used to characterize the pharmacokinetic profile of a human recombinant therapeutic protein ${ }^{35}$. As with other new biological entities, predicting the pharmacokinetic profile of therapeutic proteins from preclinical data is usually difficult owing to their human specificity. The endogenous anti-inflammatory protein hRESCAP (human recombinant rescuing alkaline phosphatase) demonstrated linear pharmacokinetics across the microdose to therapeutic-level exposure range and proceeded into phase I with use of a seamless adaptive phase $0 /$ phase I design. There are a number of additional examples where phase 0 approaches have been applied in cases of conflicting and/or inadequate preclinical data ${ }^{9,13,35,37,38,100,101,104-109,117}$ (TABLE 3).

\section{Vulnerable populations}

The inherent safety of phase $0 /$ microdosing approaches places them in an optimum position to support development of old and new drugs for populations who are routinely excluded from first-in-human studies and sometimes from clinical research altogether owing to safety concerns (for example, patients, children, women, including pregnant women, frail elderly and severely hepatically and renally impaired patients, as well as co-morbidity and polypharmacy scenarios) $^{33,140,178,179}$. Evidence-based pharmacotherapy supported by controlled clinical trials in these groups is often delayed by many years after regulatory approval in adults and in many cases is not even available. In children, only approximately half of prescriptions are made according to the label, and this has been associated with an increased frequency of adverse effects ${ }^{180-183}$. The FDA has recently issued a statement on the ethics of microdosing in paediatric patients, recommending application where the study is expected to present no more than a minimal increase over minimal risk ${ }^{140}$. Patients (as opposed to healthy individuals) also represent a vulnerable population and are at least in part routinely excluded from early-phase clinical research because of safety concerns. Other safety-related scenarios include concerns about effects of drug metabolites ${ }^{110}$.

Microdosing and other phase 0 approaches have been applied in paediatric, frail elderly and adult patient populations $^{9,76,98,100,124,125}$ (TABLE 3). Most of the progress in application of phase 0 approaches in vulnerable populations has been made in the application of microdosing in paediatric drug development, mostly in the study of drug metabolism ontogeny, and was recently incorporated into draft FDA guidance for neonatal drug development ${ }^{76,116,125,179,184,185}$. The first microdosing study in a paediatric population used AMS to characterize the pharmacokinetic profile of ${ }^{14} \mathrm{C}$-labelled ursodiol (a drug routinely used for the treatment of neonatal cholestasis) in newborns ${ }^{128}$. There were previously no controlled pharmacokinetic trial data for ursodiol to inform paediatric treatment. The microdosing study data, together with modelling, were used to describe a two-compartment model best characterizing ursodiol pharmacokinetics. Another paediatric microdosing study found paracetamol pharmacokinetic parameters were linear across the microdose to therapeutic-level range in the 0 -2-year age group ${ }^{124}$.

Microdosing studies can provide information about drug metabolites, potentially allowing compliance with guidelines such as the FDA's 'Safety Testing

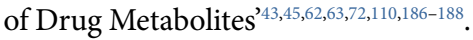
Obtaining the full metabolic profile of the test compound was one of the primary objectives in the development of AR-709, an antibiotic for the treatment of lung infections ${ }^{110}$. Owing to the high sensitivity of AMS combined with high-performance liquid chromatography, this microdosing study was able not only to characterize the pharmacokinetic profile of the parent compound but also to rule out the presence of clinically meaningful concentrations of any metabolites.

\section{PD, biomarker and/or MOA data}

Another common misconception about phase 0 and especially microdosing is that since subtherapeutic exposures are being used, no pharmacodynamic, biomarker or MOA data can be obtained. However, even exposures that do not lead to system-level macroscopic effects (that the guidelines identify as 'pharmacologically active' such as therapeutic or tolerability-related effects) can still engage in pharmacological dynamics and provide information on the so-called pillars of drug development decision-making: target compartment/ tissue disposition, binding to receptors relevant to the MOA and postreceptor modulation $^{33,70,94,189}$. Numerous examples are available from research into the methodology of phase 0 as well as from phase 0 applications in novel drug development (TABLE 3).
Formation of DNA adducts is a key step in the MOA of many oncology drugs. It can be used for characterization of chemoresistance and prediction of patient response, and can occur and be demonstrated after microdose administration $^{34,42,49,74,95}$. The efficiency of passage across the blood-brain barrier and likewise entry into tumour tissues are compartment-disposition data relevant to a drug's efficacy, and demonstration of lack of passage across the blood-brain barrier may be crucial to concerns about CNS toxicity with drugs whose efficacy targets are elsewhere ${ }^{9,65,98,115,117}$. Other examples from novel drug development include demonstration of the correlation of anti-infective efficacy with pharmacokinetics ${ }^{110}$, localization supportive of or rejecting the $\mathrm{MOA}^{9,114}$, accumulation of an amyloid imaging agent in brain regions high in amyloid deposition ${ }^{100}$, development of a novel ligand to a cancer and fibrosis target $\operatorname{\alpha v} \beta 6$ integrin $)^{127}$, and glioblastoma penetration and postreceptor modulation ${ }^{109}$. Finally, ITM has been developed and used to obtain pharmacodynamic and MOA data by administration of a microdose of the test compound directly into the target/ compartment of interest to generate therapeutic-level exposure in the target while exposing the rest of the body to microdoses (see later) ${ }^{15-17,28,66,70}$.

PET can be used to study drug effects (for example, receptor occupancy and postreceptor modulation) ${ }^{190}$. For this, a broad palette of PET tracers, which are administered at microdoses and which can quantify various aspects of drug effects, are readily available. However, for the drug to elicit a measurable effect, it generally needs to be administered at therapeutic-level doses, which do not meet the microdosing definition but it could be done with non-microdosing phase 0 approaches (for example, approaches 3, 4 and 5 in TABLE 1). Nevertheless, PET-microdosing can be applied in conjunction with administration of the drug directly into the target tissue to transiently achieve local therapeuticlevel concentrations, which in turn could lead to measurable pharmacodynamic effects (ITM) $)^{28,66,70}$.

\section{Limitations and future directions}

Drug development is a staged process that has remained essentially unchanged for more than six decades despite radical changes in the circumstances of development, most notably the exponential increase in costs in the face of unchanged 
productivity ${ }^{1,2,191-194}$. Division into stages was a practical triaging/streamlining solution to the prohibitive option of conducting expensive, definitive phase IIItype studies with all compounds entering clinical development. This reality is further accentuated in today's expensive and complex clinical development environment, justifying the consideration of adding a stage to triage candidates and streamline development at perhaps the most critical stage - that is, the translational stage, the stage with the largest gap in information in research and development, namely the transition from preclinical 'research' to clinical 'development', and the stage where phase 0 solutions reside ${ }^{195}$.

However, while showing great promise over the past two decades, the use of phase $0 /$ microdosing in industry is currently limited. This may be in part due to drug development culture and concerns related to potential developmental delays and extrapolation. Phase 0 approaches have not been fully tested and their value has not been fully assessed over a range of drug classes, targets and drug development scenarios. Phase 0 approaches may also face various methodological challenges, including timely radiolabelling of the test compound and establishment of analytical standards (BOX 2). Greater use and continued research will help address these limitations and will provide additional insights into the practical aspects of these approaches.

\section{Methodological challenges}

The main methodological concern is that of extrapolation from phase 0 subtherapeutic exposures to therapeutic-level exposures. As discussed earlier, this can be mitigated with appropriate modelling and simulation. Importantly, phase 0 extrapolation across doses complements, rather than substitutes for, the extrapolation across species from preclinical data to humans. Other challenges include the validation of targets, biomarkers and analytical standards that may be required for phase 0 studies. If these challenges, alone or in combination, are assessed to substantially adversely impact the design or conduct of the phase 0 study, then such studies should not be undertaken.

In some developmental scenarios with toxicological concerns, it might be important to obtain additional preclinical toxicological data before progressing to phase I. However, even though phase 0 exposures do not allow a direct study of toxicity in humans, PET-microdosing studies may be able to demonstrate toxicity potential, by inference, by observing unusually high concentrations in potentially sensitive tissues/ organs in humans. This might be of value in developmental scenarios with poor animal models of human disease or drug action. Thus, depending on the developmental specifics, even in such scenarios where additional toxicological data are sought, it may be of value to conduct a phase 0 study.

\section{Developmental timelines}

Potential delay to developmental timelines is a common concern raised about phase 0 approaches. However, delays can be mitigated by strategic and advanced planning and parallel conduct of phase 0 studies with preparations for phase I studies (FIG. 2). Preparations for phase 0 should start 1.5-2 years before IND application. This should allow assessment and mitigation of most phase 0 -related timeline concerns and, specifically, the assessment of potential methodological and operational challenges, such as the impact of non-linearity on data extrapolation, validation of targets, biomarkers and analytical standards, and establishment of radiolabelling protocols. Nevertheless, considerable progress has also been made in these aspects of phase 0 studies. For example, a range of versatile radiollabeling approaches have been developed that can enable labelling of almost all drugs within a few months ${ }^{196,197}$. If the assessments indicate the likelihood of significantly delayed timelines, then a dedicated benefit-risk assessment needs to be made to evaluate whether the value of the data obtained with phase 0 studies justifies the delays.

There are three components to trade off considerations regarding the utility of phase 0 approaches: costs, the value of the data and timelines. The most valuable of these components are the data and the timelines, with cost representing the component that should be traded for. In general, the value of keeping to timelines by continuing preparation for phase I in parallel with conducting phase 0 is greater than the cost of either the phase I preclinical preparations or the phase 0 programme, even if the microdosing data findings are inconsequential. Nevertheless, we acknowledge that a conclusive determination of the trade-off needs to be made with a dedicated economic analysis on a caseby-case basis until a comprehensive analysis is conducted across a range of developmental scenarios.

The COVID-19 pandemic is likely to have altered the general benefit-risk assessment of drug development in favour of enabling quicker development and quicker translation of discovery insights into clinical applications. The public health benefits that phase 0 approaches offer in terms of bringing drugs to the market and to patients in need are likely to have an increased weight in the assessment of the benefit that these approaches can provide.

\section{Drug development culture}

Drug development culture may impact the adoption of novel approaches such as phase 0 approaches. Specifically, 'truthseeking' rather than 'progression-seeking' cultures and associated incentive structures can impact the likelihood of adoption of innovative approaches ${ }^{4,164,165,198}$. It has been proposed that behavioural, cultural and organizational obstacles are the most difficult to overcome and likely represent the greatest obstacles to innovations and improvements in the drug development process $^{165}$.

In addition, the wide adoption of phase 0 approaches in industry may necessitate revision of budget structures. Currently, phase 0 budgets would fall under discovery phase budgets that may consider phase 0 to be prohibitively expensive, and potentially cost more than the entire preclinical developmental budget. However, considering the costs associated with other clinical stage studies and most importantly the potential value the data can bring to streamlining and de-risking the costly clinical development, the costs of phase 0 studies and microdosing may be justified.

\section{Future policy considerations}

Drug developers would benefit from regulatory clarity regarding both applications and operational aspects of phase 0 approaches. Regulators should use the opportunity of discovery-stage consultations with drug sponsors to address the options for phase 0 approaches and discuss regulation flexibility ${ }^{23}$. Considering phase 0 approaches in those early consultations would provide sufficient time for the full potential of their strategic advantages to be adequately planned, implemented and realized $^{33,139}$.

To enable and expand applicability and utility of phase 0 approaches, regulators should also provide clarity regarding applications in specific developmental scenarios (such as protein drug development and development in vulnerable populations), as well as when it is advisable to include patients, and address the good 
manufacturing practice and good laboratory practice standards applicable in each scenario. Currently, in some jurisdictions the same good manufacturing practice and good laboratory practice standards apply for therapeutic-level exposures as they do for microdose exposures. However, there is a case to be made as stated in the 2006 eIND guidance that more lenient standards may be justified for microdosing since microdose exposures are similar to routine environmental exposures to toxins. Regulators and health care policymakers could also assist with dissemination of the ethical, legal and social implications of phase 0 approaches. These issues have been debated in the literature and should be made familiar to sponsors, ethics committees or institutional review boards, patient advocacy groups, research operators and perhaps most importantly research participants themselves and their guarantors $^{140,142,143}$.

\section{Future research}

Topics of active methodological research include ITM, and research into the use of near-infrared fluorescence of tracers given in microdoses to guide diagnostic and therapeutic interventions (for example, surgical resections of tumours marked with fluorescent tracers targeting tumourspecific receptors) $)^{15,16,28,66,70,121,148,199}$. In addition, efforts to enhance the validity of the approaches are ongoing with the development of advanced phase 0 -specific modelling and simulations. We propose that phase 0 cohorts be added to a portion of traditional phase I studies to provide a controlled database of phase 0 performance compared with phase I performance across a range of developmental scenarios, therapeutic categories and drug classes, including correlating extrapolation of pharmacokinetic/pharmacodynamic/MOA findings from subtherapeutic phase 0 data with therapeutic-level phase I findings.

In addition to expanding applications in vulnerable populations, phase 0 research can also expand into other safety-related scenarios, such as pharmacotherapy in extreme environments. As humans venture into new environments, such as space, hyperthermic and hypothermic environments (for example, polar environments) and hyperbaric and hypobaric environments (underwater and high altitude), exposures to physiology- and pharmacology-altering conditions necessitate dedicated clinical research to inform pharmacotherapy ${ }^{200-203}$. Such environments are unlikely to have access to emergency medical services that typical research centres rely on, and hence the attractiveness of the inherent safety of phase 0 approaches ${ }^{33,138,139}$.

\section{Conclusions}

There is considerable potential for phase $0 /$ microdosing approaches to contribute to human in vivo (including patient) data to support developmental decisions at a stage when such information is typically unavailable. A large number and range of applications and associated methodological research projects have been reported in recent years. The greatest potential for impact is through the informed selection of preclinical candidates using pharmacokinetic, pharmacodynamic, biomarker and MOA data, first-in-human studies in patients, multiple simultaneous candidates (cassette microdosing), parenteral testing of enteral drugs and ITM, all potentially leading to earlier termination of non-viable candidates with the consequent invaluable savings in study costs and back-up compound patent life. However, concerns regarding extrapolation of results to therapeutic-level exposures and delays to timelines may impact certain developmental scenarios. These concerns need to be borne in mind, anticipated and mitigated or balanced against the potential benefit of the data generated.

For now, decisions on application of these approaches should be made on a case-by-case basis on the basis of the potential benefits and limitations and guided by existing reports from similar projects. In parallel, continued research into expansion of methods and applications in a range of developmental scenarios is encouraged. Eventually, a decision as to whether to routinely include these approaches as an additional stage in drug development will depend on the results of a comprehensive economic analysis that takes into account costs, time to development decisions, a range of false-positive and false-negative probabilities, across various therapeutic areas and drug categories, and the impact of early termination on the duration of development and patent-life value of pipeline compounds. However, the potential of phase 0 approaches to bring therapeutics earlier to the market, increase the safety of research participants at a critical stage of development and reduce the use of animals for human research emphasizes the wider impact and stakeholder interest that such approaches attract, as well as the points of view that need to be taken into account when their adoption is being considered.
Tal Burt (iD) 1,2四, Graeme Young (iD ${ }^{3}$, Wooin Lee ${ }^{4}$, Hiroyuki Kusuhara ${ }^{5}$, Oliver Langer ${ }^{6,7}$, Malcolm Rowland ${ }^{8}$ and Yuichi Sugiyama ${ }^{9}$

${ }^{\prime}$ Burt Consultancy LLC. talburtmd.com, New York, $N Y$, USA.

${ }^{2}$ Phase-O/Microdosing Network. Phase-OMicrodosing. org, New York, NY, USA.

${ }^{3}$ GlaxoSmithKline Research and Development Ltd, Ware, UK.

${ }^{4}$ Seoul National University, Seoul, Republic of Korea

${ }^{5}$ University of Tokyo, Tokyo, Japan.

${ }^{6}$ Medical University of Vienna, Vienna, Austria.

${ }^{7}$ AlT Austrian Institute of Technology $\mathrm{GmbH}$, Vienna, Austria.

${ }^{8}$ Manchester University, Manchester, UK.

${ }^{9}$ RIKEN, Yokohama, Japan.

凶e-mail: tburt@phase-Omicrodosing.org

https://doi.org/10.1038/s41573-020-0080-x

Published online 8 September 2020

1. FDA. Innovation or Stagnation: Challenge and Opportunity on the Critical Path to New Medical

Products. http://www.fda.gov/oc/initiatives/criticalpath whitepaper.html (2004).

2. Paul, S. M. et al. How to improve $R \& D$ productivity: the pharmaceutical industry's grand challenge. Nat. Rev. Drug Discov. 9, 203-214 (2010).

3. Scannell, J. W., Blanckley, A., Boldon, H. \& Warrington, B. Diagnosing the decline in pharmaceutical R\&D efficiency. Nat. Rev. Drug Discov. 11, 191-200 (2012).

4. Morgan, P. et al. Impact of a five-dimensional framework on $\mathrm{R} \& \mathrm{D}$ productivity at AstraZeneca. Nat. Rev. Drug Discov. 17, 167-181 (2018)

5. DiMasi, J. A., Feldman, L., Seckler, A. \& Wilson, A. Trends in risks associated with new drug development: success rates for investigational drugs. Clin. Pharmacol. Ther. 87, 272-277 (2010).

6. Swinney, D. C. \& Anthony, J. How were new medicines discovered? Nat. Rev. Drug Discov. 10, 507-519 (2011).

7. Burt, T., Button, K. S., Thom, H., Noveck, R. J. \& Munafo, M. R. The burden of the "false-negatives" in clinical development: analyses of current and alternative scenarios and corrective measures. Clin. Transl. Sci. 10, 470-479 (2017).

8. Button, K. S. et al. Power failure: why small sample size undermines the reliability of neuroscience. Nat. Rev. Neurosci. 14, 365-376 (2013).

9. Bauer, M. et al. A positron emission tomography microdosing study with a potential antiamyloid drug in healthy volunteers and patients with Alzheimer's disease. Clin. Pharmacol. Ther. 80, 216-227 (2006).

10. Byun, B. H. et al. Head-to-head comparison of ${ }^{11} \mathrm{C}-\mathrm{PiB}$ and ${ }^{18} \mathrm{~F}$-FC119S for Abeta imaging in healthy subjects, mild cognitive impairment patients, and Alzheimer's disease patients. Medicine 96, e6441 (2017).

11. Kusuhara, $\mathrm{H}$. et al. Comparison of pharmacokinetics of newly discovered aromatase inhibitors by a cassette microdosing approach in healthy Japanese subjects. Drug Metab. Pharmacokinet. 32, 293-300 (2017).

12. Xiao, H. et al. Developing a cassette microdosing approach to enhance the throughput of PET imaging agent screening. J. Pharm. Biomed. Anal. 154, 48-56 (2018).

13. Okour, M. et al. A human microdose study of the antimalarial GSK3191607 in healthy volunteers. Br. J. Clin. Pharmacol. https://doi.org/10.1111/bcp.13476 (2017).

14. Cahn, A. et al. Safety, tolerability, pharmacokinetics and pharmacodynamics of GSK2239633, a CCchemokine receptor 4 antagonist, in healthy male subjects: results from an open-label and from a randomised study. BMC Pharmacol. Toxicol. 14, 14 (2013)

15. Al Idrus, A. Presage inks its 3rd deal around phase 0 studies - with more to come. FierceBiotech https:// www.fiercebiotech.com/biotech/presage-inks-its-thirddeal-around-phase-0-studies-more-to-come (2019).

16. Jonas, O. et al. An implantable microdevice to perform high-throughput in vivo drug sensitivity testing in tumors. Sci. Transl. Med. 7, 284 ra257 (2015). 
17. Sjogren, E., Halldin, M. M., Stalberg, O. \& Sundgren-Andersson, A. K. Preclinical characterization of three transient receptor potential vanilloid receptor 1 antagonists for early use in human intradermal microdose analgesic studies. Eur. J. Pain https://doi.org/ 10.1002/ejp. 1175 (2018)

18. Gundle, K. R. et al. Multiplexed evaluation of microdosed antineoplastic agents in situ in the tumor microenvironment of patients with soft tissue sarcoma. Clin. Cancer Res. https://doi.org/10.1158/ 1078-0432. Ccr-20-0614 (2020)

19. Lappin G. \& Garner, R. C. Big physics, small doses: the use of AMS and PET in human microdosing of development drugs. Nat. Rev. Drug Discov. 2 233-240 (2003)

20. Combes, R. D. et al. Early microdose drug studies in human volunteers can minimise animal testing. proceedings of a workshop organised by volunteers in research and testing. Eur. J. Pharm. Sci. 19, 1-11 (2003).

21. Bergstrom, M., Grahnen, A. \& Langstrom, B. Positron emission tomography microdosing: a new concept with application in tracer and early clinical drug development. Eur. J. Clin. Pharmacol. 59, 357-366 (2003).

22. MHLW. Guidance: Microdose clinical Studies led. Labor and Welfare Ministry of Health, Pharmaceutical and Medical Safety Bureau) (MHLW, 2008).

23. FDA. Guidance for Industry, Investigators, and Reviewers Exploratory IND Studies. http://www.fda.gov/downloads/ Drugs/GuidanceComplianceRegulatorylnformation/ Guidances/UCM078933.pdf (2006).

24. EMEA. Position paper CPMP/SWP/2599 (2004).

25. ICH. Guidance on Nonclinical Safety Studies for the Conduct of Human Clinical Trials and Marketing Authorization for Pharmaceuticals M3(R2) 8-16 (ICH Secretariat, 2009).

26. Bertino, J. S. Jr., Greenberg, H. E. \& Reed, M. D. American college of clinical pharmacology position statement on the use of microdosing in the drug development process. J. Clin. Pharmacol. 47 418-422 (2007).

27. Rowland, M. Commentary on ACCP position statement on the use of microdosing in the drug development process. J. Clin. Pharmacol. 47, 1 595-1596 (2007). author reply 1597-1598.

28. Burt, T. et al. Intra-target microdosing (ITM): a novel drug development approach aimed at enabling safer and earlier translation of biological insights into human testing. Clin. Transl. Sci. 1-14, https://doi.org/ 10.1111/cts. 12464 (2017)

29. Bosgra, S., Vlaming, M. L. \& Vaes, W. H. To apply microdosing or not? Recommendations to single out compounds with non-linear pharmacokinetics. Clin. Pharmacokinet. 55, 1-15 (2016).

30. Lappin, G., Noveck, R. \& Burt, T. Microdosing and drug development: past, present and future. Expert Opin. Drug Metab. Toxicol. 9, 817-834 (2013).

31. Sugiyama, Y. \& Yamashita, S. Impact of microdosing clinical study - why necessary and how useful? Adv. Drug Deliv. Rev. 63, 494-502 (2011).

32. Rowland, M. Microdosing: a critical assessment of human data. J. Pharm. Sci. 101, 4067-4074 (2012).

33. Burt, T. et al. Microdosing and other phase- 0 clinical trials: facilitating translation in drug development. Clin. Transl. Sci. 9, 74-88 (2016).

34. Henderson, P. T. \& Pan, C. X. Human microdosing for the prediction of patient response. Bioanalysis 2 , 373-376 (2010)

35. Vlaming, M. et al. Microdosing of a carbon-14 labeled protein in healthy volunteers accurately predicts its pharmacokinetics at therapeutic dosages. Clin. Pharmacol. Ther. 98, 196-204 (2015).

36. van Nuland, M., Rosing, H., Huitema, A. D. R. \& Beijnen, J. H. Predictive value of microdose pharmacokinetics. Clin. Pharmacokinet. 58 1221-1236 (2019)

37. Malfatti, M. A., Lao, V., Ramos, C. L., Ong, V. S. \& Turteltaub, K. W. Use of microdosing and accelerator mass spectrometry to evaluate the pharmacokinetic linearity of a novel tricyclic GyrB/ParE inhibitor in rats. Antimicrob. Agents Chemother. 58, 6477-6483 (2014).

38. Sandhu, P. et al. Evaluation of microdosing strategies for studies in preclinical drug development demonstration of linear pharmacokinetics in dogs of a nucleoside analog over a 50-fold dose range. Drug Metab. Dispos. 32, 1254-1259 (2004).

39. Snoeys, J., Beumont, M., Monshouwer, M. \& Ouwerkerk-Mahadevan, S. Mechanistic understanding of the nonlinear pharmacokinetics and intersubject variability of simeprevir: a PBPK-guided drug development approach. Clin. Pharmacol. Ther. 99, 224-234 (2016)

40. Pierrillas, P. B. et al. Prediction of human nonlinear pharmacokinetics of a new $\mathrm{Bcl}-2$ inhibitor using PBPK modeling and interspecies extrapolation strategy. Drug Metab. Dispos. 47, 648-656 (2019).

41. Lappin, G. et al. Use of microdosing to predict pharmacokinetics at the therapeutic dose: experience with 5 drugs. Clin. Pharmacol. Ther. 80, 203-215 (2006).

42. Hah, S. S., Sumbad, R. A., de Vere White, R. W. Turteltaub, K. W. \& Henderson, P. T. Characterization of oxaliplatin-DNA adduct formation in DNA and differentiation of cancer cell drug sensitivity at microdose concentrations. Chem. Res. Toxicol. 20, 1745-1751 (2007).

43. Yamane, N. et al. Microdose clinical trial: quantitative determination of nicardipine and prediction of metabolites in human plasma. Drug Metab. Pharmacokinet. 24, 389-403 (2009).

44. Lappin, G. et al. Pharmacokinetics of fexofenadine: evaluation of a microdose and assessment of absolute oral bioavailability. Eur. J. Pharm. Sci. 40, 125-131 (2010).

45. Ni, J. et al. Sensitivity and proportionality assessment of metabolites from microdose to high dose in rats using LC-MS/MS. Bioanalysis 2, 407-419 (2010).

46. Prueksaritanont, $\mathrm{T}$. et al. Validation of a microdose probe drug cocktail for clinical drug interaction assessments for drug transporters and CYP3A. Clin. Pharmacol. Ther. 101, 519-530 (2017).

47. Wagner, C. C. et al. A combined accelerator mass spectrometry-positron emission tomography human microdose study with ${ }^{14} \mathrm{C}$ - and ${ }^{11} \mathrm{C}$-labelled verapamil. Clin. Pharmacokinet. 50, 111-120 (2010).

48. Yamazaki, A et al. Microdose study of a P-glycoprotein substrate, fexofenadine, using a non-radioisotope-labelled drug and LC/MS/MS . J. Clin. Pharm. Ther. 35, 169-175 (2010).

49. Henderson, P. T. et al. A microdosing approach for characterizing formation and repair of carboplatinDNA monoadducts and chemoresistance. Int. J. Cancer 129, 1425-1434 (2011).

50. Ieiri, I. et al. Microdosing clinical study: pharmacokinetic, pharmacogenomic (SLCO2B1), and interaction (grapefruit juice) profiles of celiprolo following the oral microdose and therapeutic dose. J. Clin. Pharmacol. 52, 1078-1089 (2011).

51. Ieiri, I. et al. Pharmacokinetic and pharmacogenomic profiles of telmisartan after the oral microdose and therapeutic dose. Pharmacogenet. Genomics 21 495-505 (2011)

52. Kusuhara, $\mathrm{H}$. et al. Effects of a MATE protein inhibitor pyrimethamine, on the renal elimination of metformin at oral microdose and at therapeutic dose in healthy subjects. Clin. Pharmacol. Ther. 89, 837-844 (2011).

53. Lappin, G. et al. Comparative pharmacokinetics between a microdose and therapeutic dose for clarithromycin, sumatriptan, propafenone, paracetamol (acetaminophen), and phenobarbital in human volunteers. Eur. J. Pharm. Sci. 43, 141-150 (2011).

54. Maeda, K. et al. Identification of the rate-determining process in the hepatic clearance of atorvastatin in a clinical cassette microdosing study. Clin. Pharmacol. Ther 90, 575-581 (2011).

55. Maeda, K. \& Sugiyama, Y. Novel stratergies for microdose studies using non-radiolabeled compounds. Adv. Drug Deliv. Rev. 63, 532-538 (2011)

56. Maeda, K et al. Nonlinear pharmacokinetics of oral quinidine and verapamil in healthy subjects: a clinical microdosing study. Clin. Pharmacol. Ther. 90 263-270 (2011)

57. Minamide, Y., Osawa, Y., Nishida, H., Igarashi, H. ¿ Kudoh, S. A highly sensitive LC-MS/MS method capable of simultaneously quantitating celiprolol and atenolol in human plasma for a cassette coldmicrodosing study. J. Separ. Sci. 34, 1590-1598 (2011).

58. Yamane, N. et al. Clinical relevance of liquid chromatography tandem mass spectrometry as an analytical method in microdose clinical studies. Pharm. Res. 28, 1963-1972 (2011).

59. Chen, J. et al. Biphasic elimination of tenofovir diphosphate and nonlinear pharmacokinetics of zidovudine triphosphate in a microdosing study. J. Acquir. Immune Defic. Syndr. 61, 593-599 (2012).

60. Croft, M., Keely, B., Morris, I., Tann, L. \& Lappin, G. Predicting drug candidate victims of drug-drug interactions, using microdosing. Clin. Pharmacokinet. 51, 237-246 (2012)

61. leiri, I. et al. Pharmacogenomic/pharmacokinetic assessment of a four-probe cocktail for CYPs and OATPs following oral microdosing. Int. J. Clin. Pharmacol. Ther. 50, 689-700 (2012).

62. Cho, D. Y., Bae, S. H., Shon, J. H. \& Bae, S. K High-sensitive LC-MS/MS method for the simultaneous determination of mirodenafil and its major metabolite, SK-3541, in human plasma: application to microdose clinical trials of mirodenafil. J. Separ. Sci. 36 840-848 (2013)

63. Ikeda, T. et al. Microdose pharmacogenetic study of ${ }^{14} \mathrm{C}$-tolbutamide in healthy subjects with accelerator mass spectrometry to examine the effects of CYP2C9*3 on its pharmacokinetics and metabolism. Eur. J. Pharm. Sci. 49, 642-648 (2013).

64. Lamers, R. J., de Jong, A. F., Lopez-Gutierrez, J. M. \& Gomez-Guzman, J. lodine-129 microdosing for protein and peptide drug development: erythropoietin as a case study. Bioanalysis 5, 53-63 (2013).

65. Schou, M. et al. Radiolabeling of the cannabinoid receptor agonist AZD1940 with carbon-11 and PET microdosing in non-human primate. Nucl. Med. Biol. 40, 410-414 (2013).

66. Burt, T. et al. Intraarterial microdosing: a novel drug development approach, proof-of-concept PET study in rats. J. Nucl. Med. 56, 1793-1799 (2015).

67. Fujita, K. et al. A clinical pharmacokinetic microdosing study of docetaxel with Japanese patients with cancer. Cancer Chemother. Pharmacol. 76, 793-801 (2015).

68. Yamashita, S. et al. An assessment of the oral bioavailability of three Ca-channel blockers using a cassette-microdose study: a new strategy for streamlining oral drug development. J. Pharm. Sci. 104, 3154-3161 (2015).

69. Madeen, E. P. et al. Human microdosing with carcinogenic polycyclic aromatic hydrocarbons: in vivo pharmacokinetics of dibenzo[def,p]chrysene and metabolites by UPLC accelerator mass spectrometry. Chem. Res. Toxicol. 29, 1641-1650 (2016).

70. Burt, T. et al. Intra-target microdosing - a novel drug development approach: proof of concept, safety, and feasibility study in humans. Clin. Transl. Sci. https://doi.org/10.1111/cts.12477 (2017).

71. Park, G. J. et al. Drug-drug interaction of microdose and regular-dose omeprazole with a CYP2C19 inhibitor and inducer. Drug Des. Devel. Ther. 11, 1043-1053 (2017).

72. van Nuland, M. et al. Ultra-sensitive LC-MS/MS method for the quantification of gemcitabine and its metabolite 2',2'-difluorodeoxyuridine in human plasma for a microdose clinical trial. J. Pharm. Biomed. Anal. 151, 25-31 (2017).

73. Wang, S. S. et al. A diagnostic microdosing approach to investigate platinum sensitivity in non-small cell lung cancer. Int. J. Cancer 141, 604-613 (2017).

74. Zimmermann, M. et al. Microdose-induced drug-DNA adducts as biomarkers of chemotherapy resistance in humans and mice. Mol. Cancer Ther. 16, 376-387 (2017).

75. Hohmann, N. et al. Simultaneous phenotyping of CYP2E 1 and CYP3A using oral chlorzoxazone and midazolam microdoses. Br. J. Clin. Pharmacol. https://doi.org/10.1111/bcp.14040 (2019).

76. van Groen, B. D. et al. Dose-linearity of the pharmacokinetics of an intravenous $\left[{ }^{14} \mathrm{C}\right]$ midazolam microdose in children. Br. J. Clin. Pharmacol. https://doi.org/10.1111/bcp. 14047 (2019).

77. Takashima, T. et al. PET imaging-based evaluation of hepatobiliary transport in humans with (15R)-11C-TICMe. J. Nucl. Med. 53, 741-748 (2012).

78. Hohmann, N., Halama, B., Siller, N., Mikus, G. \& Haefeli, W. E. Response to "Can CYP3A activity be evaluated for drug interaction using a nanogram dose of probe drug?": evaluation of CYP3A activity with microdoses of midazolam. Clin. Pharmacol. Ther 95 490-491 (2014)

79. Halama, B. et al. A nanogram dose of the CYP3A probe substrate midazolam to evaluate drug interactions. Clin. Pharmacol. Ther. 93, 564-571 (2013).

80. Burhenne, J. et al. Quantification of femtomolar concentrations of the CYP3A substrate midazolam and its main metabolite 1'-hydroxymidazolam in human plasma using ultra performance liquid chromatography coupled to tandem mass spectrometry. Anal. Bioanal. Chem. 402, 2439-2450 (2012).

81. Hohmann, N. et al. Midazolam microdose to determine systemic and pre-systemic metabolic CYP3A activity in humans. Br. J. Clin. Pharmacol 79, 278-285 (2015) 
82. Schou, $\mathrm{M}$. et al. Large variation in brain exposure of reference CNS drugs: a PET study in nonhuman primates. Int. J. Neuropsychopharmacol. 18 https://doi.org/10.1093/ijnp/pyv036 (2015).

83. Madeen, E. et al. Human in vivo pharmacokinetics of $\left[{ }^{14} \mathrm{C}\right]$ dibenzo[def,p]chrysene by accelerator mass spectrometry following oral microdosing. Chem. Res. Toxicol. https://doi.org/10.1021/tx5003996 (2014)

84. Saleem, A. et al. Lapatinib access into normal brain and brain metastases in patients with Her-2 overexpressing breast cancer. EJNMMI Res. 5, 30 (2015).

85. Saleem, A., Aboagye, E. O., Matthews, J. C. \& Price, P. M. Plasma pharmacokinetic evaluation of cytotoxic agents radiolabelled with positron emitting radioisotopes. Cancer Chemother. Pharmacol. 61 865-873 (2008)

86. Saleem, A. et al. Pharmacokinetic evaluation of $\mathrm{N}$-[2-(dimethylamino)ethyl]acridine-4-carboxamide in patients by positron emission tomography. J. Clin. Oncol. 19, 1421-1429 (2001)

87. leiri, I. et al. Mechanisms of pharmacokinetic enhancement between ritonavir and saquinavir micro/small dosing tests using midazolam (CYP3A4), fexofenadine (p-glycoprotein), and pravastatin (OATP1B1) as probe drugs. J. Clin. Pharmacol. 53, 654-661 (2013)

88. van der Veldt, A. A Smit, E. F. \& Lammertsma, A. A. Positron emission tomography as a method for measuring drug delivery to tumors in vivo: the example of ["1 C]docetaxel. Front. Oncol. 3, 208 (2013).

89. Shin, K. H. et al. A positron emission tomography microdosing study with sertraline in healthy volunteers. Int. J. Clin. Pharmacol. Ther. 50, 224-232 (2012).

90. Vuong, L. T. et al. Use of accelerator mass spectrometry to measure the pharmacokinetics and peripheral blood mononuclear cell concentrations of zidovudine. J. Pharm. Sci. 97, 2833-2843 (2008).

91. Cunningham, V. J. et al. A method of studying pharmacokinetics in man at picomolar drug concentrations. Br. J. Clin. Pharmacol. 32, 167-172 (1991).

92. Liu, L. et al. Modulation of P-glycoprotein at the human blood-brain barrier by quinidine or rifampin treatment: a positron emission tomography imaging study. Drug Metab. Dispos. 43, 1795-1804 (2015).

93. Van Nuland, M. et al. Pilot study to predict pharmacokinetics of a therapeutic gemcitabine dose from a microdose. Clin. Pharmacol. Drug Dev. https://doi.org/10.1002/cpdd.774 (2020).

94. Ordonez, A. A. et al. Dynamic imaging in patients with tuberculosis reveals heterogeneous drug exposures in pulmonary lesions. Nat. Med. 26 529-534 (2020)

95. Zimmermann, M et al Oxaliplatin-DNA adducts as predictive biomarkers of FOLFOX response in colorectal cancer: a potential treatment optimization strategy. Mol. Cancer Ther. 19, 1070-1079 (2020).

96. Mikus, G. et al. Application of a microdosed cocktail of 3 oral factor Xa inhibitors to study drug-drug interactions with different perpetrator drugs. $\mathrm{Br}$. J. Clin. Pharmacol. https://doi.org/10.1111/bcp.14277 (2020).

97. Madan, A. et al. A pharmacokinetic evaluation of five $\mathrm{H} 1$ antagonists after an oral and intravenous microdose to human subjects. Br. J. Clin. Pharmacol. 67, 288-298 (2008)

98. Heuveling, D. A. et al. Phase 0 microdosing PET study using the human mini antibody F16SIP in head and neck cancer patients. J. Nucl. Med. 54, 397-401 (2013).

99. Kummar, S. et al. First-in-human phase 0 trial of oral 5-iodo-2-pyrimidinone-2'-deoxyribose in patients with advanced malignancies. Clin. Cancer Res. 19 , 1852-1857 (2013)

100. Carpenter, A. P. Jr., Pontecorvo, M. J., Hefti, F. F. \& Skovronsky, D. M. The use of the exploratory IND in the evaluation and development of 18F-PET radiopharmaceuticals for amyloid imaging in the brain: a review of one company's experience. Q. J. Nucl. Med. Mol. Imaging 53, 387-393 (2009).

101. Zhou, X. J., Garner, R. C., Nicholson, S., Kissling, C. J. \& Mayers, D. Microdose pharmacokinetics of IDX899 and IDX989, candidate HIV-1 non-nucleoside reverse transcriptase inhibitors, following oral and intravenous administration in healthy male subjects. J. Clin. Pharmacol. 49, 1408-1416 (2009).

102. Wang, J. L. et al. The novel benzopyran class of selective cyclooxygenase- 2 inhibitors. Part III: the three microdose candidates. Bioorg Med. Chem. Lett. 20, 7164-7168 (2010)

103. Sun, L. et al. Ultrasensitive liquid chromatographytandem mass spectrometric methodologies for quantification of five HIV-1 integrase inhibitors in plasma for a microdose clinical trial. Anal. Chem. $\mathbf{8 4}$, 8614-8621 (2012)

104. Jones, H. M. et al. Clinical micro-dose studies to explore the human pharmacokinetics of four selective inhibitors of human Nav 1.7 voltage-dependent sodium channels. Clin. Pharmacokinet. 55, 875-887 (2016).

105. Ostenfeld, T., Beaumont, C., Bullman, J., Beaumont, M. $\&$ Jeffrey, P. Human microdose evaluation of the novel EP1 receptor antagonist GSK269984A. Br. J. Clin. Pharmacol. 74, 1033-1044 (2012).

106. Harrison, A. et al. Case studies addressing human pharmacokinetic uncertainty using a combination of pharmacokinetic simulation and alternative first in human paradigms. Xenobiotica 42, 57-74 (2012).

107. Park, W.-S. et al. Human microdosing and mice xenograft data of AGM-130 applied to estimate efficacious doses in patients. Cancer Chemother. Pharmacol. 80, 363-369 (2017).

108. Rajagopalan, R. et al. Preclinical characterization and human microdose pharmacokinetics of ITMN-8187, a nonmacrocyclic inhibitor of the hepatitis C virus NS3 protease. Antimicrob. Agents Chemother. 61, https:// doi.org/10.1128/aac.01569-16 (2017)

109. Sanai, N. et al. Phase 0 trial of AZD 1775 in firstrecurrence glioblastoma patients. Clin. Cancer Res. https://doi.org/10.1158/1078-0432.ccr-17-3348 (2018).

110. Lappin, G. et al. A microdose study of ${ }^{14} \mathrm{C}-\mathrm{AR}-709$ in healthy men: pharmacokinetics, absolute bioavailability and concentrations in key compartments of the lung. Eur. J. Clin. Pharmacol. 69, 1673-1682, https:// doi.org/10.1007/s00228-013-1528-2 (2013).

111. Bal, C. et al. Pharmacokinetic, dosimetry and toxicity study of ${ }^{177}$ Lu-EDTMP in patients: phase 0/l study. Curr. Radiopharm. 9, 71-84 (2016).

112. Reid, J. M. et al. Phase 0 clinical chemoprevention trial of the Akt inhibitor SR13668. Cancer Prev. Res. 4, 347-353 (2011).

113. Kummar, S. et al. Phase 0 clinical trial of the poly (ADP-ribose) polymerase inhibitor ABT-888 in patients with advanced malignancies. J. Clin. Oncol. 27 2705-2711 (2009).

114. Kaplan, N., Garner, C. \& Hafkin, B. AFN-1252 in vitro absorption studies and pharmacokinetics following microdosing in healthy subjects. Eur. J. Pharm. Sci. 50, 440-446 (2013).

115. Johnstrom, P. et al. Development of rapid multistep carbon- 11 radiosynthesis of the myeloperoxidase inhibitor AZD3241 to assess brain exposure by PET microdosing. Nucl. Med. Biol. 42, 555-560 (2015).

116. Mooij, M. G. et al. Pediatric microdose study of $\left[{ }^{14} \mathrm{C}\right]$ paracetamol to study drug metabolism using accelerated mass spectrometry: proof of concept Clin. Pharmacokinet. 53, 1045-1051 (2014).

117. Barthel, H. et al. Individualized quantification of brain beta-amyloid burden: results of a proof of mechanism phase 0 florbetaben PET trial in patients with Alzheimer's disease and healthy controls. Eur. J. NuCl. Med. Mol. Imaging 38, 1702-1714 (2011).

118. Moschos, S. J. et al. Pharmacodynamic (phase 0) study using etaracizumab in advanced melanoma. J. Immunother. 33, 316-325 (2010).

119. Park, M. H. et al. Validation of a liquid chromatography-triple quadrupole mass spectrometric method for the determination of 5-nitro-5'-hydroxyindirubin-3'-oxime (AGM-130) in human plasma and its application to microdose clinical trial. Biomed. Chromatogr. https://doi.org/10.1002/bmc.3551 (2015).

120. Elliott, J. T. et al. Microdose fluorescence imaging of ABY-029 on an operating microscope adapted by custom illumination and imaging modules. Biomed. Opt. Express 7, 3280-3288 (2016).

121. Lamberts, L. E. et al. Tumor-specific uptake of fluorescent bevacizumab-IRDye800CW microdosing in patients with primary breast cancer: a phase I feasibility study. Clin. Cancer Res. 23, 2730-2741 (2017).

122. de Souza, A. L. et al. Fluorescent affibody molecule administered in vivo at a microdose level labels EGFR expressing glioma tumor regions. Mol. Imaging Biol. 19, 41-48 (2017).

123. Jonas, O. et al. Parallel in vivo assessment of drug phenotypes at various time points during systemic BRAF inhibition reveals tumor adaptation and altered treatment vulnerabilities. Clin. Cancer Res. 22 6031-6038 (2016)

124. Garner, C. R. et al. Observational infant exploratory $\left[{ }^{14} \mathrm{C}\right]$-paracetamol pharmacokinetic microdose/ therapeutic dose study with accelerator mass spectrometry bioanalysis. Br. J. Clin. Pharmacol. 80, 157-167 (2015).

125. Mooij, M. G. et al. Successful use of $\left[{ }^{14} \mathrm{C}\right]$ paracetamol microdosing to elucidate developmental changes in drug metabolism. Clin. Pharmacokinet. https://doi.org/ 10.1007/s40262-017-0508-6 (2017).

126. Byun, B. H., K, B. \& Lim, I. H. Quantification of amyloid-b deposition using ${ }^{18} \mathrm{~F}-\mathrm{FC} 119 \mathrm{~S}$ PET in human brains: a phase 0-1 study. Eur. J. Nucl. Med. Mol. Imaging https://doi.org/10.1007/s00259-015-3198-z (2015).

127. Keat, N. et al. A microdose PET study of the safety, immunogenicity, biodistribution, and radiation dosimetry of ${ }^{18} \mathrm{~F}$-FB-A20FMDV2 for imaging the integrin alphavbeta6. J. Nucl. Med. Technol. 46, 136-143 (2018)

128. Gordi, T. et al. Pharmacokinetic analysis of ${ }^{14} \mathrm{C}$-ursodiol in newborn infants using accelerator mass spectrometry. J. Clin. Pharmacol. 54, 1031-1037 (2014).

129. Lesche, R. et al. Preclinical evaluation of BAY 1075553, a novel F-labelled inhibitor of prostatespecific membrane antigen for PET imaging of prostate cancer. Eur. J. Nucl. Med. Mol. Imaging https://doi.org/10.1007/s00259-013-2527-3 (2013).

130. Bauer, M. et al. Pgp-mediated interaction between (R)- $\left[{ }^{11} \mathrm{C}\right]$ verapamil and tariquidar at the human blood-brain barrier: a comparison with rat data. Clin. Pharmacol. Ther. 91, 227-233 (2012).

131. Wei, X., Zhang, Z., Xie, Y. \& Wang, Y. [Phase 0 clinical trials and post-marketed re-evaluation of clinical safety in injection of traditional Chinese medicine]. Zhongguo Zhong Yao Za Zhi 36, 2874-2876 (2011).

132. Kuwano, K. et al. 2-[4-[(5,6-Diphenylpyrazin-2-yl) (isopropyl)amino]butoxy]-N-(methylsulfonyl)acetamide (NS-304), an orally available and long-acting prostacyclin receptor agonist prodrug. J. Pharmacol. Exp. Ther. 322, 1181-1188 (2007).

133. Jacobs, B. A. et al. A phase 0 clinical trial of nove candidate extended-release formulations of capecitabine. Cancer Chemother. Pharmacol. 77. 1201-1207 (2016).

134. Kurdziel, K. A. et al. First-in-human phase 0 study of "11'In-CHX-A"-DTPA trastuzumab for HER2 tumor imaging. J. Transl. Sci. 5, https://doi.org/10.15761/ jts. 1000269 (2019).

135. Wang, S. J. et al. A phase 0 study of the pharmacokinetics, biodistribution, and dosimetry of ${ }^{188} \mathrm{Re}$-liposome in patients with metastatic tumors. EJNMMI Res. 9, 46 (2019).

136. Kaneko, K. et al. A clinical quantitative evaluation of hepatobiliary transport of $\left[{ }^{11} \mathrm{C}\right]$ dehydropravastatin in humans using positron emission tomography. Drug Metab. Dispos. 46, 719-728 (2018).

137. Tien, A. C. et al. A phase 0 trial of ribociclib in recurrent glioblastoma patients incorporating a tumor pharmacodynamic- and pharmacokinetic-guided expansion cohort. Clin. Cancer Res. 25, 5777-5786 (2019).

138. Burt, T. et al. Phase 0 , including microdosing approaches: applying the three Rs and increasing the efficiency of human drug development. Altern. Lab. Anim. 46, 335-346 (2018)

139. Burt, T., John, C. S., Ruckle, J. L. \& Vuong, L. T. Phase-O/microdosing studies using PET, AMS, and LC-MS/MS: a range of study methodologies and conduct considerations. Accelerating development of novel pharmaceuticals through safe testing in humans - a practical guide. Expert Opin. Drug Deliv. 1-16, https://doi.org/10.1080/17425247.2016.1227786 (2016).

140. Roth-Cline, M. \& Nelson, R. M. Microdosing studies in children: a US regulatory perspective. Clin. Pharmacol. Ther. 98, 232-233 (2015).

141. Burt, T., Combes, R. D. in The History of Alternative Test Methods in Toxicology (eds Combes, R. D., Balls, M. \& Worth, A.) 229-240 (Elsevier/Academic Press, 2018).

142. Kurihara, C. Ethical, legal, and social implications (ELSI) of microdose clinical trials. Adv. Drug Deliv. Rev. 63, 503-510 (2011)

143. Kimmelman, J. Ethics at phase 0: clarifying the issues. J. Law Med. Ethics 35, 514 (2007).

144. McCartt, A. D., Ognibene, T. J., Bench, G. \& Turteltaub, K. W. Quantifying carbon-14 for biology using cavity ring-down spectroscopy. Anal. Chem. $\mathbf{8 8}$ 8714-8719 (2016). 
145. Zhang, Y. \& Fox, G. B. PET imaging for receptor occupancy: meditations on calculation and simplification. J. Biomed. Res. 26, 69-76 (2012)

146. Wagner, C. C. \& Langer, O. Approaches using molecular imaging technology - use of PET in clinical microdose studies. Adv. Drug Deliv. Rev. 63 539-546 (2011)

147. Sugiyama, Y. Effective use of microdosing and positron emission tomography (PET) studies on new drug discovery and development. Drug Metab. Pharmacokinet. 24, 127-129 (2009).

148. Pogue, B. W. et al. Vision 20/20: molecular-guided surgical oncology based upon tumor metabolism or immunologic phenotype: technological pathways for point of care imaging and intervention. Med. Phys. 43, 3143-3156 (2016)

149. Dueker, S. R., Vuong le, T., Lohstroh, P. N., Giacomo, J. A $\&$ Vogel, J. S. Quantifying exploratory low dose compounds in humans with AMS. Adv. Drug Deliv. Rev. 63, 518-531 (2011).

150. Dueker, S. R. et al. Early human ADME using microdoses and microtracers: bioanalytical considerations. Bioanalysis 2, 441-454 (2010).

151. Rowland, M., Benet, L. Z. \& Lead, P. K. commentary: predicting human pharmacokinetics. J. Pharm. Sci. 100, 4047-4049 (2011).

152. Takano, J., Maeda, K., Bolger, M. B. \& Sugiyama, Y. The prediction of the relative importance of CYP3A/P-glycoprotein to the nonlinear intestinal absorption of drugs by advanced compartmental absorption and transit model. Drug Metab. Dispos. 44, 1808-1818 (2016)

153. Ito, K., Iwatsubo, T., Kanamitsu, S., Nakajima, Y. \& Sugiyama, Y. Quantitative prediction of in vivo drug clearance and drug interactions from in vitro data on metabolism, together with binding and transport. Annu. Rev. Pharmacol. Toxicol. 38, 461-499 (1998).

154. Chiba, M., Ishii, Y. \& Sugiyama, Y. Prediction of hepatic clearance in human from in vitro data for successful drug development. AAPS J. 11, 262-276 (2009).

155. van Waterschoot, R. A. B. et al. Impact of target interactions on small-molecule drug disposition: an overlooked area. Nat. Rev. Drug Discov. 17, 299 (2018).

156. Smith, D. A. et al. Importance of target-mediated drug disposition for small molecules. Drug Discov. Today 23, 2023-2030 (2018)

157. An, G. Small-molecule compounds exhibiting targetmediated drug disposition (TMDD): a minireview. J. Clin. Pharmacol. 57, 137-150 (2017)

158. Levy, G. Pharmacologic target-mediated drug disposition. Clin. Pharmacol. Ther. 56, 248-252 (1994).

159. Mager, D. E. \& Jusko, W. J. General pharmacokinetic model for drugs exhibiting target-mediated drug disposition. J. Pharmacokinet. Pharmacodyn. $\mathbf{2 8}$ 507-532 (2001)

160. Yamane, N. et al. Cost-effectiveness analysis of microdose clinical trials in drug development. Drug Metab. Pharmacokinet. 28, 187-195 (2013).

161. Sugiyama, Y. \& Kurihara, C. Microdosing Clinical Trials (Jiho, 2007)

162. Rowland, M. in Microdosing and the $3 R$ s (National Centre for the Replacement, Refinement and Reduction of Animals in Research (NC3Rs) 2006).

163. Owens, P. K. et al. A decade of innovation in pharmaceutical R\&D: the Chorus model. Nat. Rev. Drug Discov. 14, 17-28 (2015).

164. Lendrem, D. W. et al. Progression-seeking bias and rational optimism in research and development. Nat. Rev. Drug Discov. 14, 219-221 (2015).

165. Peck, R. W., Lendrem, D. W., Grant, I., Lendrem, B. C. \& Isaacs, J. D. Why is it hard to terminate failing projects in pharmaceutical R\&D? Nat. Rev. Drug Discov. 14, 663-664 (2015)

166. Wong, C. H., Siah, K. W. \& Lo, A. W. Estimation of clinical trial success rates and related parameters. Biostatistics 20, 273-286 (2019).

167. Pammolli, F., Magazzini, L. \& Riccaboni, M. The productivity crisis in pharmaceutical R\&D. Nat. Rev. Drug Discov. 10, 428-438 (2011).

168. Pammolli, F. et al. The endless frontier? The recent increase of $R \& D$ productivity in pharmaceuticals. J. Transl. Med. 18, 162 (2020).

169. Morgan, S., Grootendorst, P., Lexchin, J., Cunningham, C. \& Greyson, D. The cost of drug development: a systematic review. Health Policy 100, 4-17 (2011).
170. Zhou, H., Tong, Z. \& McLeod, J. F. "Cocktail” approaches and strategies in drug development: valuable tool or flawed science? J. Clin. Pharmacol. 44, 120-134 (2004)

171. Manitpisitkul, P. \& White, R. E. Whatever happened to cassette-dosing pharmacokinetics? Drug Discov. Today 9, 652-658 (2004)

172. Mikus, G. Probes and cocktails for drug-drug interaction evaluation: the future is microdosing? Clin. Pharmacol. Ther. (2019).

173. Chavez-Eng, C. M., Lutz, R. W., Goykhman, D. \& Bateman, K. P. Microdosing cocktail assay development for drug-drug interaction studies. J. Pharm. Sci. 107 1973-1986 (2018)

174. Zhang, L. \& Sparreboom, A. Predicting transportermediated drug interactions: Commentary on: "Pharmacokinetic evaluation of a drug transporter cocktail consisting of digoxin, furosemide, metformin and rosuvastatin" and "Validation of a microdose probe drug cocktail for clinical drug interaction assessments for drug transporters and CYP3A". Clin. Pharmacol. Ther 101, 447-449 (2017).

175. Rowland, M., Benet, L. Z. \& Graham, G. G. Clearance concepts in pharmacokinetics. J. Pharmacokinet. Biopharm. 1, 123-136 (1973)

176. Waldman, S. A. \& Terzic, A. Process improvement for maximized therapeutic innovation outcome. Clin. Pharmacol. Ther. 103, 8-12 (2018).

177. Gunn, R. N. et al. Combining PET biodistribution and equilibrium dialysis assays to assess the free brain concentration and BBB transport of CNS drugs. J. Cereb. Blood Flow. Metab. 32, 874-883 (2012).

178. Roth-Cline, M. \& Nelson, R. M. Ethical considerations in conducting pediatric and neonatal research in clinica pharmacology. Curr. Pharm. Des. 21, 5619-5635 (2015).

179. Turner, M. A. et al. Pediatric microdose and microtrace studies using ${ }^{14} \mathrm{C}$ in Europe. Clin. Pharmacol. Ther. 98, 234-237 (2015)

180. Bellis, J. R. et al. Adverse drug reactions and off-label and unlicensed medicines in children: a nested casecontrol study of inpatients in a pediatric hospital. BMC Med. 11, 238 (2013).

181. Dunne, J. et al. Extrapolation of adult data and other data in pediatric drug-development programs. Pediatrics 128, e1242-e1249 (2011).

182. Yackey, K. \& Stanley, R. Off-label prescribing in children remains high: a call for prioritized research Pediatrics https://doi.org/10.1542/peds.2019-157 (2019).

183. EU. Study on off-label use of medicinal products in the European Union https://doi.org/10.2875/464022 (EU, 2017).

184. Vuong, L. T., Blood, A. B., Vogel, J. S., Anderson, M. E. $\&$ Goldstein, B. Applications of accelerator MS in pediatric drug evaluation. Bioanalysis 4, 1871-1882 (2012).

185. FDA. General Clinical Pharmacology Considerations for Neonatal Studies for Drugs and Biological Products Guidance for Industry (FDA, 2019).

186. Tozuka, Z. et al. Microdose study of ${ }^{14} \mathrm{C}$-acetaminophen with accelerator mass spectrometry to examine pharmacokinetics of parent drug and metabolites in healthy subjects. Clin. Pharmacol. Ther. 88, 824-830 (2010).

187. Lappin, G. \& Garner, R. C. in Handbook of Analytical Separations, . Vol. 4. Bioanalytical separations 331-349 (Elsevier, 2003)

188. FDA. Safety Testing of Drug Metabolites (FDA, 016).

189. Morgan, P. et al. Can the flow of medicines be improved? Fundamental pharmacokinetic and pharmacological principles toward improving phase II survival. Drug Discov. Today 17, 419-424 (2012).

190. Lee, C. M. \& Farde, L. Using positron emission tomography to facilitate CNS drug development. Trends Pharmacol Sci. $27,310-316$ (2006).

191. DiMasi, J. A., Grabowski, H. G. \& Hansen, R. W. Innovation in the pharmaceutical industry: new estimates of R\&D costs. J. Health Econ. 47, 20-33 (2016).

192. DiMasi, J. A., Grabowski, H. G. \& Hansen, R. W. The cost of drug development. N. Engl. J. Med. 372 1972 (2015).

193. DiMasi, J. A., Hansen, R. W. \& Grabowski, H. G The price of innovation: new estimates of drug development costs. J. Health Econ. 22, 151-185 (2003).

194. Munos, B. Lessons from 60 years of pharmaceutica innovation. Nat. Rev. Drug Discov. 8, 959-968 (2009).
195. Coller, B. S. \& Califf, R. M. Traversing the valley of death: a guide to assessing prospects for translational success. Sci. Transl. Med. 1, $10 \mathrm{~cm} 19$ (2009).

196. Dahl, K., Halldin, C. \& Schou, M. New methodologies for the preparation of carbon-11 labeled radiopharmaceuticals. Clin. Transl. Imaging 5, 275-289 (2017).

197. Li, Z. \& Conti, P. S. Radiopharmaceutical chemistry for positron emission tomography. Adv. Drug Deliv. Rev. 62, 1031-1051 (2010)

198. Cook, D. et al. Lessons learned from the fate of AstraZeneca's drug pipeline: a five-dimensional framework. Nat. Rev. Drug Discov. 13, 419-431 (2014).

199. Samkoe, K. S. et al. Toxicity and pharmacokinetic profile for single-dose injection of ABY-029: a fluorescent anti-EGFR synthetic affibody molecule for human use. Mol. Imaging Biol. 19, 512-521 (2017).

200. Du, B. et al. Evaluation of physical and chemical changes in pharmaceuticals flown on space missions. AAPS J. 13, 299-308 (2011).

201. Stenstrom, K., Sydoff, M. \& Mattsson, S. Microdosing for early biokinetic studies in humans. Radiat. Prot. Dosimetry 139, 348-352 (2010).

202. Eyal, S. How do the pharmacokinetics of drugs change in astronauts in space? Expert Opin. Drug Metab. Toxicol. https://doi.org/10.1080/17425255.2020.17 46763 (2020).

203. Eyal, S. \& Derendorf, H. Medications in space: in search of a pharmacologist's guide to the galaxy. Pharm. Res. 36, 148 (2019).

204. Iwatsubo, T., Suzuki, H. \& Sugiyama, Y. Prediction of species differences (rats, dogs, humans) in the in vivo metabolic clearance of YM796 by the liver from in vitro data. J. Pharmacol. Exp. Ther. 283, 462-469 (1997).

205. Iwatsubo, T., Hirota, N., Ooie, T., Suzuki, H. \& Sugiyama, $Y$. Prediction of in vivo drug disposition from in vitro data based on physiological pharmacokinetics. Biopharm. Drug Dispos. 17 273-310 (1996)

206. Chen, M. et al. An ultra-sensitive LC-MS/MS method to determine midazolam levels in human plasma: development, validation and application to a clinica study. Bioanalysis 9, 297-312 (2017).

207. Garner, R. C. Practical experience of using human microdosing with AMS analysis to obtain early human drug metabolism and PK data. Bioanalysis 2, 429-440 (2010)

208. Young, G., Ellis, W., Ayrton, J., Hussey, E. \& Adamkiewicz, B. Accelerator mass spectrometry (AMS): recent experience of its use in a clinical study and the potential future of the technique. Xenobiotica 31, 619-632 (2001)

209. Turteltaub, K. W. \& Dingley, K. H. Application of accelerated mass spectrometry (AMS) in DNA adduct quantification and identification. Toxicol. Lett. 102-103, 435-439 (1998)

210. Bergstrom, M. The use of microdosing in the development of small organic and protein therapeutics. J. Nucl. Med. 58, 1188-1195 (2017)

211. Wagner, C. C., Muller, M., Lappin, G. \& Langer, O. Positron emission tomography for use in microdosing studies. Curr. Opin. Drug Discov. Devel. 11, 104-110 (2008)

212. Bauer, M., Wagner, C. C. \& Langer, O. Microdosing studies in humans: the role of positron emission tomography. Drugs RD 9, 73-81 (2008).

213. Shebley, M. et al. Physiologically based pharmacokinetic model qualification and reporting procedures for regulatory submissions: a consortium perspective. Clin. Pharmacol. Ther. 104, 88-110 (2018).

214. Thorneloe, K. S. et al. The biodistribution and clearance of AlbudAb, a novel biopharmaceutical medicine platform, assessed via PET imaging in humans. EJNMMI Res. 9, 45 (2019).

\section{Acknowledgements}

The authors acknowledge the members of the Phase-0/ Microdosing Network, an international consortium of phase 0 stakeholders, and especially E. Baker, M. Bergström, P. Choyke, M. Croft, S. de Wildt, J. DiMasi, S. Dueker, U. Glaenzel, I. Hallett, P. T. Henderson, O. Jonas, K. Lee, M. Okour, I. Rabiner, A. Roffel, W. Vaes, E. van Duijn, B. van Groen, L. Vuong, I. Yamada and H. Yamazaki for their review and/or contribution to the formulation of the concepts in this Perspective. Some of the Phase-0/Microdosing Network's discussions that helped refine consensus concepts included in this Perpsective were held at the First International Phase-0/Microdosing Stakeholder Meeting, 12 March 2019, Washington (DC, USA). 


\section{PERSPECTIVES}

\section{Author contributions}

T.B., W.L. and Y.S contributed to researching data for this article. T.B., G.Y., W.L., O.L., H.K., M.R. and Y.S. made substantial contributions to discussion of the content, writing of the manuscript and reviewing the manuscript before submission.

\section{Competing interests}

Y.B. is President of the Phase-0/Microdosing Network, a non-profit educational organization dedicated to phase 0 including microdosing approaches and receives fees for consultations that may be impacted by this publication. G.Y is employed by GlaxoSmithKline Research and Development Ltd and holds shares in the company. T.B., Y.S., M.R. and O.L. are members of the Phase-0/Microdosing Network Board of Directors. All authors are members of the Phase-0/Microdosing Network.

Publisher's note

Springer Nature remains neutral with regard to jurisdictional claims in published maps and institutional affiliations.

\section{Supplementary information}

Supplementary information is available for this paper at https://doi.org/10.1038/s41573-020-0080-x.

\section{RELATED LINKS}

Phase-0/Microdosing Network

https://phase-0microdosing.org/

(C) Springer Nature Limited 2020 